\title{
Evaluation of WRF Mesoscale Climate Simulations over the Tibetan Plateau during 1979-2011
}

\author{
YANHONG GAO AND JIANWEI XU \\ Key Laboratory of Land Surface Process and Climate Change in Cold and Arid Regions, Cold and Arid Regions \\ Environmental and Engineering Research Institute, Chinese Academy of Sciences, Lanzhou, China \\ DELIANG CHEN \\ Department of Earth Sciences, University of Gothenburg, Gothenburg, Sweden
}

(Manuscript received 22 April 2014, in final form 24 December 2014)

\begin{abstract}
To develop a finescale dataset for the purpose of analyzing historical climatic change over the Tibet Plateau (TP), a high-resolution regional climate simulation for 1979-2011 was conducted using the Weather Research and Forecasting (WRF) Model driven by the ERA-Interim (ERA-Int). This work evaluates the high-resolution $(30 \mathrm{~km})$ WRF simulation in terms of annual variation, spatial structure, and 33-yr temporal trends of surface air temperature (Tair) and precipitation (Prec) over the TP, with reference to station observations. Another focus is on the examination of the height-temperature relationship. Inheriting from its forcing, the WRF simulation presents an apparent cold bias in the TP. The cold bias is largely reduced by a lapse rate correction of the simulated surface air temperature with help of the station and model elevations. ERA-Int presents the same sign of Tair and Prec trends as the observations, but with smaller magnitude, especially in the dry season. Compared to its forcing, the WRF simulation improves the simulation of the annual cycles and temporal trends of Tair and Prec in the wet season. In the dry season, however, there is hardly any improvement. The observed Tair presents a downward linear trend in the lapse rate. This feature is examined in the WRF simulation in comparison to ERA-Int. The WRF simulation captures the observed lapse rate and its temporal trend better than ERA-Int. The decreasing lapse rate over time confirms that Tair change in the TP is elevation dependent.
\end{abstract}

\section{Introduction}

The Tibetan Plateau (TP) stands over $4000 \mathrm{~m}$ above sea level, and is the highest and most extensive highland in the world (Fig. 1). The landscape is characterized by extremely varied topography with a highland complex of mountains. The mountainous terrain over the TP results in a host of finescale weather systems and varied regional and local climate. Climatology and climate changes over the TP have been widely analyzed using observations. One of the most important findings is that the TP has undergone faster warming rate than global average in the past three decades (Liu and Chen 2000; Wu et al. 2007; Solomon et al. 2007; Krause et al. 2010;

Corresponding author address: Yanhong Gao, Cold and Arid Regions Environmental and Engineering Research Institute, CAS, 320 Donggang West Rd., Lanzhou, Gansu 730000, China. E-mail: gaoyh@lzb.ac.cn
Moore 2012). The TP has gained growing attention recently (e.g., Jacob et al. 2012) because of its significant role in global and regional atmospheric circulation and its sensitivity to human induced climate change. However, because of the harsh environment conditions, observation sites are sparely scattered over the TP where humans have relatively easy access. Moreover, most observation sites are located in the eastern TP (e.g., Su et al. 2013). Over a large portion of the vast northwestern TP, there is not a single observation site. Therefore, there is an unavoidable uncertainty in climate change analysis with in situ observations due to the poorly gauged observation network over the TP. There are a number of global and regional gridded datasets covering the whole TP (e.g., Mitchell and Jones 2005; Adler et al. 2003; Xu et al. 2009; Chen et al. 2010; Wu and Gao 2013). However, since all of them only rely on station data, which are sparse over the TP, the usefulness of these gridded products for the TP is limited. 
(a)

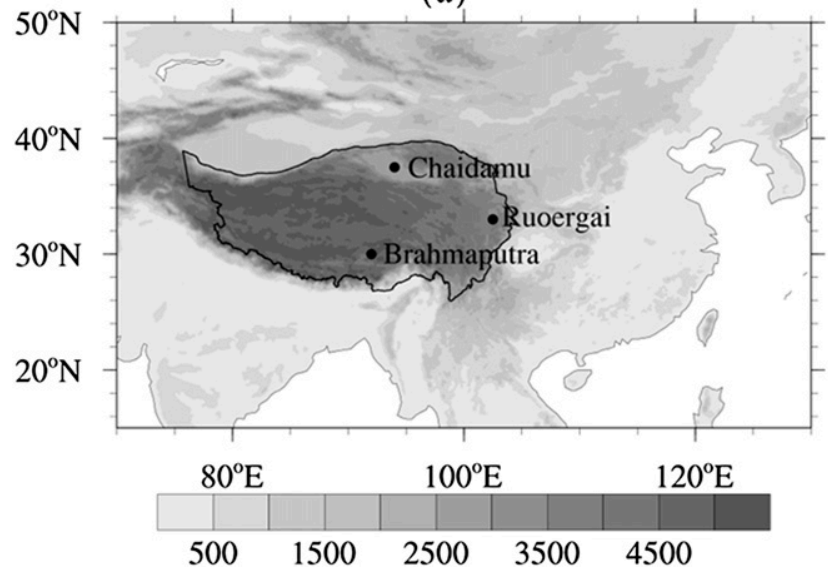

(b)

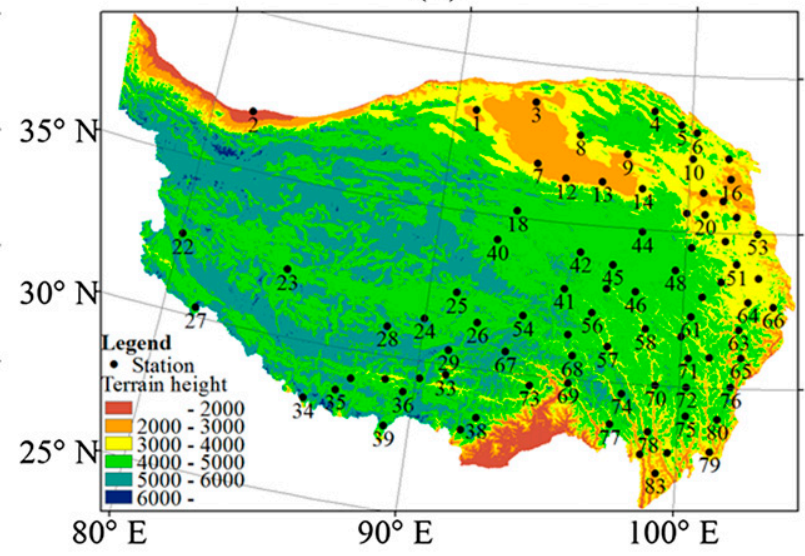

FIG. 1. (a) Simulation domain and topography (m) and (b) locations of the meteorological stations with topography used in this study.

Global climate models (GCMs) can resolve largescale weather systems (Meehl et al. 2007; Randall et al. 2007). Thus they have been widely used to explore and project the large-scale climate change. However, formulation of adaptation measures in response to climate change requires information at finer spatial scales (Gao et al. 2011a; Y. Gao et al. 2012). More importantly, there are important processes operating at scales smaller than those that are resolved by GCMs. This is particularly true for heterogeneous regions such as the TP.

Accurate estimates of regional-scale climate are required to better understand regional climate change (Betts et al. 1996; Entekhabi et al. 1996). There are basically two ways to downscale the coarse-resolution GCM results to finer scale. One is statistical downscaling (Benestad et al. 2008; Wilks 1995) and another is dynamic downscaling (Y. Gao et al. 2012; X. Gao et al. 2012). The dynamic downscaling method uses a regional climate model (RCM), in which GCM outputs are used as initial and lateral boundary conditions for more spatially detailed climatological simulations over a region of interest.

Dynamic downscaling has been widely applied for downscaling reanalysis data and global climate simulations to study regional climate and climate change in North America, Europe, Africa, and Asia (Mearns et al. 2009; Déqué et al. 2005; Duffy et al. 2006; Ghan et al. 2006; Giorgi et al. 1992; Kim et al. 2002; Leung et al. 2003a,b; Plummer et al. 2006; Zhang et al. 2009; Laprise et al. 1998; Gao et al. 2006; Zhang et al. 2005). The Coordinated Regional Climate Downscaling Experiment (CORDEX; http://www.meteo.unican.es/en/projects/ CORDEX; Giorgi et al. 2009) is a World Climate Research Programme (WCRP)-sponsored program to organize an international coordinated framework to produce an improved generation of regional climate change projections worldwide for input into impact and adaptation studies within the IPCC Fifth Assessment Report (AR5) timeline and beyond. There are quite several multi-RCM intercomparison projects over different continents. For instance, over the North America, the North American Regional Climate Change Assessment Program (NARCCAP; Mearns et al. 2009; Leung et al. 2006) aims to produce high-resolution climate change simulations and generate climate change scenarios for impacts research. The African Monsoon Multidisciplinary Analysis (AMMA) climate system model intercomparison over West Africa is another example. Over Asia, numerous regional simulations have been conducted. Impacts of various parameterizations on the regional climate simulation were explored and combinations for better reproducing regional climate were suggested (Gao et al. 2008; Gao et al. 2011b; Xu and Gao 2014). Advantages of the high-resolution regional climate and climate change simulation in the surface air temperature and precipitation over eastern China were documented (Gao et al. 2006; Yu et al. 2010; Li et al. 2005; Zhang et al. 2008). Some researchers have investigated climate changes in recent decades (Hirakuchi and Giorgi 1995; Gao et al. 2001), as well as paleoclimate (Ju et al. 2007) over East Asia. Because of the scarcity observations over the TP, there is little literature focusing on the analysis of the regional simulation over the TP. Zhang et al. (2005) performed a simulation using RegCM3 over the Qinghai-Xizang Plateau. However, their results suffer from systematic errors from the single model used. To avoid the uncertainty from a specific RCM in the TP, more simulations utilizing other RCMs are necessary, along the lines of most continental regional model intercomparison experiments. Furthermore, the elevationdependent warming (EDW) has been documented in the literature using observations. However, to our 
knowledge, no RCM runs have been involved in the EDW studies so far.

This study focuses on a long-term (1979-2011) WRF simulation, downscaling the ERA-Interim (Dee and Uppala 2009; Dee et al. 2011). The most important issue in downscaling is under what conditions it is really capable of improving/adding more climate information at smaller scales compared to the driving GCM or reanalysis, especially when an RCM is run for a long time. In this paper, we evaluate the WRF simulations of the surface air temperature (Tair) and precipitation (Prec) over the TP compared to in situ observations. The EDW issue will also be discussed using the WRF simulation with respective to the observation and its coarse-resolution forcing. The objectives of this study are 1) to evaluate the performance of WRF over the TP at a fine scale and over a long term and 2) to examine the added value of the WRF simulations in comparison to the driving reanalysis, which has a coarser spatial resolution. We will proceed in the following manner. Section 2 briefly describes the model, simulations, data used, and methodology. Section 3 compares model simulations with the observations. Major conclusions and discussion are presented in section 4.

\section{Model, simulations, data, and methodology}

\section{a. Model and simulations}

The Weather Research and Forecasting (WRF) Model (http://www.wrf-model.org/index.php; Skamarock et al. 2005) is a mesoscale numerical weather prediction system designed to serve both operational forecasting and atmospheric research needs. It is a nonhydrostatic model, with several available dynamic cores as well as many different choices for physical parameterizations suitable for a broad spectrum of application across scales from meters to thousands of kilometers. It has been widely used around the world. The dynamic cores in WRF include a fully mass- and scalar-conserving flux from mass coordinate version. The physics packages includes microphysics, cumulus parameterization, planetary boundary layer, shortwave and longwave radiation, and land surface models. In this simulation, the shortwave and longwave radiations were computed by the NCAR Community Atmospheric Model (CAM) shortwave scheme and longwave scheme (Collins et al. 2004) following Leung et al. (2003a,b) with WRF configuration in NARCCAP (Mearns et al. 2009), which has been successfully used in long-term simulation over North America. Considering the importance of the microphysics processes over the TP, we did a series of tests on the impact of the microphysics parameterizations in Tair and Prec simulation among six schemes over the TP. There is not much difference in Tair and Prec simulations among these microphysics parameterizations over the TP (not shown). To save computing resources, the WRF Single-Moment 3-class scheme (WSM3) was used in the simulation as in Leung et al. (2003a,b). The convective parameterization used is the Grell-Devenyi ensemble scheme (Grell 1993) following NARCCAP. The Yonsei University (YSU) scheme (Hong and Pan 1996) was used for the PBL parameterization. The land surface model (LSM) used here is the Noah LSM four-layer soil temperature and moisture model with frozen soil and snow cover prediction (Chen and Dudhia 2001).

WRF was set up with 30-km horizontal grid spacing with $159 \times 196$ grid cells, which covers nearly the whole Asian continent (Fig. 1a) following Exp. 6 in Gao et al. (2011b). The vertical levels were set to 27 with the model top at $50 \mathrm{hPa}$. Simulation was initialized at $0000 \mathrm{UTC}$ 1 January 1979 and ended at 2300 UTC 31 December 2011. Following NARCCAP, the lateral boundary conditions and SST were updated every $6 \mathrm{~h}$ and the simulation was outputted in 3-h intervals.

\section{b. Data}

The initial lateral boundary conditions and SST were interpolated from ERA-Interim (1979-present; Dee and Uppala 2009; Dee et al. 2011). ERA-Interim (hereafter ERA-Int) is an improved version of ERA-40. An updated ECMWF forecasting model version cycle 31r1 is used with a horizontal resolution of approximately $80 \mathrm{~km}$ for ERA-Int. Aside from the improved resolution over ERA-40, ERA-Int utilizes four-dimensional variational data assimilation (4DVar) and bias correction of satellite radiance data (Dee and Uppala 2009), better formulation of background error constraint, new humidity analysis, and improved model physics. ERA-Int also uses mostly the sets of observations acquired for ERA-40, supplemented by data for later years from ECMWF's operational archive. In addition, ERA-Int makes extensive use of radiances such as altimeter wave heights and radio occultation measurements. As with ERA-40, the land surface analysis for ERA-Int incorporates $2-\mathrm{m}$ air temperature and relative humidity observation to improve the land surface model temperature and soil moisture fields. ERA-Int has been proven to be the best among reanalysis products available in describing temperature and water cycle over the TP (Wang and Zeng 2012; Gao et al. 2014).

Surface air temperature and precipitation observations are provided by the National Climate Center, China 
TABLE 1. Geographical information [longitude $\left({ }^{\circ} \mathrm{E}\right)$, latitude $\left({ }^{\circ} \mathrm{N}\right)$, and station elevation (HGT, $\left.\mathrm{m} \mathrm{MSL}\right)$ ] of the 83 stations over the TP and MSL elevations ( $\mathrm{m}$ ) at the stations in ERA-Int (ERA; $\mathrm{m} \mathrm{MSL)} \mathrm{and} \mathrm{WRF} \mathrm{(} \mathrm{m} \mathrm{MSL}$ ) and their differences with HGT. The elevations in ERA-Int and WRF are interpolated to station locations using bilinear interpolation.

\begin{tabular}{|c|c|c|c|c|c|c|c|c|}
\hline No. & Name & Lon & Lat & HGT & ERA-Int & ERA-Int - HGT & WRF & WRF - HGT \\
\hline 1 & Amang & 90.9 & 38.3 & 2944.8 & 3342.6 & 397.8 & 3076.2 & 131.4 \\
\hline 2 & Yutian & 81.7 & 36.9 & 1422.0 & 1854.9 & 432.9 & 1407.2 & -14.8 \\
\hline 3 & Lenghu & 93.3 & 38.8 & 2770.0 & 2917.4 & 147.4 & 2855.7 & 85.7 \\
\hline 4 & Tuole & 98.4 & 38.8 & 3367.0 & 3796 & 429.0 & 3850.0 & 483.0 \\
\hline 5 & Yeniugou & 99.6 & 38.4 & 3320.0 & 3510.7 & 190.7 & 3906.1 & 586.1 \\
\hline 6 & Qilian & 100.3 & 38.2 & 2787.4 & 3383.5 & 596.1 & 3342.7 & 555.3 \\
\hline 7 & Xiaozaohuo & 93.7 & 36.8 & 2767.0 & 3089.3 & 322.3 & 2750.6 & -16.4 \\
\hline 8 & Dachaidan & 95.4 & 37.9 & 3173.2 & 3520.6 & 347.4 & 3702.4 & 529.2 \\
\hline 9 & Delingha & 97.4 & 37.4 & 2981.5 & 3612.2 & 630.7 & 3234.5 & 253 \\
\hline 10 & Gangcha & 100.1 & 37.3 & 3301.5 & 3607 & 305.5 & 3463.9 & 162.4 \\
\hline 11 & Mengyuan & 101.6 & 37.4 & 2850.0 & 3197.3 & 347.3 & 3490.1 & 640.1 \\
\hline 12 & Geermu & 94.9 & 36.4 & 2807.6 & 3350.1 & 542.5 & 2977.2 & 169.6 \\
\hline 13 & Nuomuhong & 96.4 & 36.4 & 2790.4 & 3326.9 & 536.5 & 2829.8 & 39.4 \\
\hline 14 & Dulan & 98.1 & 36.3 & 3189.0 & 3595.3 & 406.3 & 3331.9 & 142.9 \\
\hline 15 & Qiabuqia & 100.6 & 36.3 & 2835.0 & 3241.3 & 406.3 & 3032.9 & 197.9 \\
\hline 16 & Xining & 101.8 & 36.7 & 2295.2 & 3032.6 & 737.4 & 2751.4 & 456.2 \\
\hline 17 & Guide & 101.4 & 36.0 & 2237.1 & 3105.7 & 868.6 & 3207.3 & 970.2 \\
\hline 18 & Wudaoliang & 93.1 & 35.2 & 4612.2 & 4685.7 & 73.5 & 4622.4 & 10.2 \\
\hline 19 & Xinghai & 100.0 & 35.6 & 3323.2 & 3709.2 & 386.0 & 3511.3 & 188.1 \\
\hline 20 & Guinan & 100.7 & 35.6 & 3120.0 & 3480.9 & 360.9 & 3401.1 & 281.1 \\
\hline 21 & Tongren & 102.0 & 35.5 & 2491.4 & 3293.9 & 802.5 & 3339.9 & 848.5 \\
\hline 22 & Shiquanhe & 80.1 & 32.5 & 4278.6 & 4926.5 & 647.9 & 4887.0 & 608.4 \\
\hline 23 & Gaize & 84.4 & 32.2 & 4414.9 & 4859.9 & 445.0 & 4660.1 & 245.2 \\
\hline 24 & Bange & 90.0 & 31.4 & 4700.0 & 4815.2 & 115.2 & 4960.6 & 260.6 \\
\hline 25 & Amduo & 91.1 & 32.4 & 4800.0 & 4892.6 & 92.6 & 4846.7 & 46.7 \\
\hline 26 & $\mathrm{Naqu}$ & 92.1 & 31.5 & 4507.0 & 4841.6 & 334.6 & 4609.4 & 102.4 \\
\hline 27 & Pulan & 81.3 & 30.3 & 3900.0 & 4351.5 & 451.5 & 4814.6 & 914.6 \\
\hline 28 & Shenzha & 88.6 & 31.0 & 4672.0 & 4997.9 & 325.9 & 4912.2 & 240.2 \\
\hline 29 & Dangxiong & 91.1 & 30.5 & 4200.0 & 4901.1 & 701.1 & 4897.0 & 697.0 \\
\hline 30 & Lazi & 87.6 & 29.1 & 4000.0 & 4854.5 & 854.5 & 4450.0 & 450.0 \\
\hline 31 & Rikeze & 88.9 & 29.3 & 3836.0 & 4710.2 & 874.2 & 4279.5 & 443.5 \\
\hline 32 & Nimu & 90.2 & 29.4 & 3809.4 & 4857.9 & 1048.5 & 4677.7 & 868.3 \\
\hline 33 & Lasa & 91.1 & 29.7 & 3648.9 & 4694.3 & 1045.4 & 4604.4 & 955.5 \\
\hline 34 & Nielari & 86.0 & 28.2 & 3810.0 & 3844.5 & 34.5 & 4587.2 & 777.2 \\
\hline 35 & Dingri & 87.1 & 28.6 & 4300.0 & 4912.9 & 612.9 & 4893.1 & 593.1 \\
\hline 36 & Jiangzi & 89.6 & 28.9 & 4040.0 & 4779.7 & 739.7 & 4310.1 & 270.1 \\
\hline 37 & Cuona & 92.0 & 28.0 & 4280.0 & 4012.1 & -267.9 & 4584.6 & 304.6 \\
\hline 38 & Longzi & 92.5 & 28.4 & 3860.0 & 4466.8 & 606.8 & 4818.8 & 958.8 \\
\hline 39 & Pali & 89.1 & 27.7 & 4300.0 & 3978.6 & -321.4 & 4834.3 & 534.3 \\
\hline 40 & Tuotuohe & 92.4 & 34.2 & 4533.1 & 4747.3 & 214.2 & 4599.9 & 66.8 \\
\hline 41 & Zaduo & 95.3 & 32.9 & 4066.4 & 4715.3 & 648.9 & 4609.3 & 542.9 \\
\hline 42 & Qumalai & 95.8 & 34.1 & 4175.0 & 4657.8 & 482.8 & 4625.0 & 450.0 \\
\hline 43 & Yushu & 97.0 & 33.0 & 3716.9 & 4437.5 & 720.6 & 4430.1 & 713.2 \\
\hline 44 & Maduo & 98.2 & 34.9 & 4272.3 & 4391.1 & 118.8 & 4293.5 & 21.2 \\
\hline 45 & Qingshuihe & 97.1 & 33.8 & 4415.4 & 4498.2 & 82.8 & 4465.2 & 49.8 \\
\hline 46 & Shiqu & 98.1 & 33.0 & 4200.0 & 4426.6 & 226.6 & 4320.0 & 120.0 \\
\hline 47 & Guoluo & 100.2 & 34.5 & 3719.0 & 4117.0 & 398 & 4033.7 & 314.7 \\
\hline 48 & Dari & 99.7 & 33.8 & 3967.5 & 4356.9 & 389.4 & 4190.9 & 223.4 \\
\hline 49 & Henan & 101.6 & 34.7 & 3500.0 & 3732.5 & 232.5 & 3714.9 & 214.9 \\
\hline 50 & Jiuzhi & 101.5 & 33.4 & 3628.5 & 3931.1 & 302.6 & 3920 & 291.5 \\
\hline 51 & Maqu & 102.1 & 34.0 & 3471.4 & 3698.2 & 226.8 & 3556.9 & 85.5 \\
\hline 52 & Ruoergai & 103.0 & 33.6 & 3441.4 & 3506.5 & 65.1 & 3513.5 & 72.1 \\
\hline 53 & Hezuo & 102.9 & 35.0 & 2910.0 & 3125.0 & 215.0 & 3200.9 & 290.9 \\
\hline 54 & Suoxian & 93.8 & 31.9 & 4022.8 & 4803 & 780.2 & 4529.6 & 506.8 \\
\hline 55 & Dingqing & 95.6 & 31.4 & 3873.1 & 4617.2 & 744.1 & 4733.3 & 860.2 \\
\hline 56 & Nangqian & 96.5 & 32.2 & 3643.7 & 4428.1 & 784.4 & 4361.9 & 718.2 \\
\hline
\end{tabular}


TABLE 1. (Continued)

\begin{tabular}{|c|c|c|c|c|c|c|c|c|}
\hline No. & Name & Lon & Lat & HGT & ERA-Int & ERA-Int - HGT & WRF & WRF - HGT \\
\hline 57 & Changdu & 97.2 & 31.2 & 3315.0 & 4409.2 & 1094.2 & 4130.1 & 815.1 \\
\hline 58 & Deluo & 98.6 & 31.8 & 3184.0 & 4479.5 & 1295.5 & 4859.2 & 1675.2 \\
\hline 59 & Ganzi & 100.0 & 31.6 & 3393.5 & 4268.6 & 875.1 & 4064.6 & 671.1 \\
\hline 60 & Banma & 100.8 & 32.9 & 3530.0 & 4141.2 & 611.2 & 4077.7 & 547.7 \\
\hline 61 & Seda & 100.3 & 32.3 & 3893.9 & 4201.1 & 307.2 & 4239.4 & 345.5 \\
\hline 62 & Daofu & 101.1 & 31.0 & 2957.2 & 4077.6 & 1120.4 & 3871.2 & 914 \\
\hline 63 & Maerkang & 102.2 & 31.9 & 2664.4 & 3881.2 & 1216.8 & 4000.9 & 1336.5 \\
\hline 64 & Hongyuan & 102.6 & 32.8 & 3491.6 & 3749.8 & 258.2 & 3828.8 & 337.2 \\
\hline 65 & Xiaojin & 102.4 & 31.0 & 2438.0 & 3516.1 & 1078.1 & 3364.6 & 926.6 \\
\hline 66 & Songpan & 103.6 & 32.7 & 2850.7 & 3331.2 & 480.5 & 3589.4 & 738.7 \\
\hline 67 & Jiali & 93.3 & 30.7 & 4488.8 & 4934.6 & 445.8 & 5079.8 & 591.0 \\
\hline 68 & Luolong & 95.8 & 30.8 & 3640.0 & 4569.9 & 929.9 & 4583.5 & 943.5 \\
\hline 69 & Bomi & 95.8 & 29.9 & 2736.0 & 4121.0 & 1385.0 & 3886.1 & 1150.1 \\
\hline 70 & Batang & 99.1 & 30.0 & 2589.2 & 4283.6 & 1694.4 & 3920.6 & 1331.4 \\
\hline 71 & Xinlong & 100.3 & 30.9 & 3000.0 & 4264.8 & 1264.8 & 4272.2 & 1272.2 \\
\hline 72 & Litang & 100.3 & 30.0 & 3948.9 & 4311.5 & 362.6 & 4459.2 & 510.3 \\
\hline 73 & Linzhi & 94.3 & 29.7 & 2991.8 & 4056.5 & 1064.7 & 4476.7 & 1484.9 \\
\hline 74 & Zuogong & 97.8 & 29.7 & 3780.0 & 4261.0 & 481.0 & 4371.7 & 591.7 \\
\hline 75 & Daocheng & 100.3 & 29.1 & 3727.7 & 4120.6 & 392.9 & 4361.5 & 633.8 \\
\hline 76 & Kangding & 102.0 & 30.1 & 2615.7 & 3485.7 & 870.0 & 3762.9 & 1147.2 \\
\hline 77 & Chayu & 97.5 & 28.7 & 2327.6 & 3744.1 & 1416.5 & 3716.5 & 1388.9 \\
\hline 78 & Deqin & 98.9 & 28.5 & 3319.0 & 3756.5 & 437.5 & 3703.3 & 384.3 \\
\hline 79 & Muli & 101.3 & 27.9 & 2426.5 & 3039.4 & 612.9 & 3039.5 & 613.0 \\
\hline 80 & Jiulong & 101.5 & 29.0 & 2925.0 & 3662.3 & 737.3 & 4077.7 & 1152.7 \\
\hline 81 & Gongshan & 98.7 & 27.8 & 1583.3 & 2911.5 & 1328.2 & 3064.1 & 1480.8 \\
\hline 82 & Zhongdian & 99.7 & 27.8 & 3276.7 & 3371.6 & 94.9 & 3443.8 & 167.1 \\
\hline 83 & Weixi & 99.3 & 27.2 & 2326.1 & 2884.5 & 558.4 & 2901.0 & 574.9 \\
\hline Mean & & & & 3442.4 & 4004.5 & 562.1 & 3987.4 & 545.0 \\
\hline
\end{tabular}

Meteorological Administration (CMA). Figure 1b shows the locations of the 83 stations covering the period 1979-2011.

\section{c. Methodology}

Model simulations from WRF and ERA-Int are compared to observations at 83 CMA stations. The details of these stations are indicated in Table 1 . We choose to use the station observations directly for the comparison because the majority of the existing gridded dataset used a smaller number of stations than we have in this study, and there are large areas over the TP without observation.

Comparison is conducted on monthly-mean Tair and Prec in places where we have observational stations. First, Tair values at the nearest grid cells of the model were compared to the observations. Second, the ERAInt and the WRF simulations were interpolated to station locations using bilinear interpolation. Since the in situ observation sites are mostly located in the valley where humans have easy access and the model topographies may differ from the reality and differ from each other, there are elevation differences between the model grid cells and in situ observation sites (Table 1). The differences in topography have great influence on temperature over mountainous regions. To account for the elevation difference between grid cell and observation sites and the impact on Tair, a step called lapse rate correction was conducted for the simulated Tair after the bilinear interpolation. The monthly-mean lapse rates at stations were estimated using surface air temperatures from 81 neighboring grid cells in the WRF simulation and 25 in the ERA-Int. Here, the different grid numbers are used to ensure that the lapse rate calculated covers the same domain. When compared to the lapse rate estimated using in situ observations, there are often not enough neighbors due to the scarcity of the stations. The lapse rate is calculated using the surface air temperature and station elevations at a given region to meet the stations required in the lapse rate calculation (Fang and Yoda 1988; Li et al. 2013).

No lapse rate correction was applied to precipitation since the lapse rate for precipitation is not as well defined as that for temperature due to complicated nature of relevant processes for precipitation in mountain areas, although some studies (e.g., Achberger et al. 2003) do show an elevation dependence in a small area. Seasonal and annual climatology and climate change of the WRF simulations are evaluated by comparing with observations at the 83 stations and those from ERA-Int, 
which has a larger spatial resolution than that of the WRF simulation.

Climatology in the TP is split into a dry season (October-April) and wet season (May-September) according to typical seasonal variation of the precipitation in the region (Yao et al. 2013; Gao et al. 2014). Seasonal climatology and changes in Tair and Prec for the dry and wet seasons are analyzed in the following.

\section{Results}

\section{a. Tair}

Figure 2 shows the seasonal variation of Tair and its monthly temporal trend during 1979 and 2011 from the ERA-Int and the WRF simulations averaged over all grids in which there is a at least one station. ERA-Int and the WRF simulation both have a seasonal underestimation in Tair of $2^{\circ}-5^{\circ} \mathrm{C}$ compared to observations. It is obvious that the differences between those taken from the nearest grid cells and those from the bilinear interpolation are negligible because of the lack of information at the station scale from the models, but the lapse rate correction significantly reduces the underestimation (Fig. 2a). This demonstrates the importance of elevation to temperature and indicates that the elevations of the WRF and the model used by the ERAInt deviate fairly significantly from those at the stations. This is not surprising given the complex terrain in the $\mathrm{TP}$, which is not resolved at the station scale in the models used, and the usual positioning of the stations. The underestimation without lapse rate correction implies that the models' grids have higher elevation than those of the stations. This is confirmed by Table 1, which displays the elevations at the stations, as well as those used in ERA-Int and WRF. The majority of the stations have a lower elevation than the model grid cells, which is consistent with the cold biases in both ERA-Int and the WRF simulation. In fact, CMA stations over the TP are mostly situated at valleys. Therefore, the elevations of the stations are usually lower than the average elevations of the corresponding grid cells in the models. Apparently, the underestimations are to a large extent removed by the lapse rate correction (Fig. 2a, Table 3). Indeed, the seasonal cycles of surface air temperatures in ERA-Int and the WRF simulations match the observation very well after the lapse rate correction. Figure 2a shows that the averaged biases in ERA-Int and the WRF simulations are all less than $0.5^{\circ} \mathrm{C}$ for the dry and wet seasons and the annual mean (Table 2). A closer examination of Fig. 2a shows that ERA-Int possesses a smaller bias than the WRF simulation in the cold season, especially in the southern TP (Figs. 3a,d). This means that the WRF simulations in the cold season did not add value to the reanalysis with regard to the bias. Su et al. (2013) demonstrate that GCMs tend to have poorer performance for temperature in the cold season than in the warming season. Snow cover dynamics was proposed as a possible process that was not properly described in the models. This is why special attention was given to the snow parameterization over the TP in one of the CMIP models (Wu et al. 2010). The same might hold here too. While ERA-Int has incorporated other observed information in addition to the surface air temperature in the assimilation system, the WRF simulation has to rely on its own simulation of relevant processes for snow. Thus, the snow cover in the WRF may have not been realistically simulated. Since the simulated Tair is significantly improved after the lapse rate correction in both the WRF simulation and ERA-Int, we will only analyze results after the lapse rate correction for Tair in the following.

Figure $2 \mathrm{~b}$ shows the seasonal temporal trends during 1979 and 2011 estimated from the stations as well as from ERA-Int and the WRF simulations. While the seasonal pattern is generally well simulated by WRF and ERA-Int, the WRF and ERA-Int estimates have a smaller magnitude than the observations, with an exception for WRF estimate in June. Unlike the observations of Tair, temperatures at the surface height in the models represent a mean value over a height range, which may partly explain the difference in the trends. Table 3 reveals that the observed monthly-mean Tair averaged over all the stations has a higher warming rate in the dry season than that in the wet season. This comes from a larger warming rate at stations in the central TP in the dry season than in the wet season (Figs. 4a,b). ERA-Int shows smaller warming rates than the observation for both seasons (Table 3) in the central and southern TP (Figs. 4d,e). The WRF simulation mostly inherits the ERA-Int estimate of the Tair trends except for May-July, when the WRF simulates the trends realistically in the wet season (Figs. $2 \mathrm{~b}$ and $4 \mathrm{~h}$, Table 3 ). This improvement originates from closer mean trend, smaller RMSE, and higher significant pattern correlation between WRF and observations than ERA-Int in the wet season (Table 3), especially in the central TP where the relative large warming rate is not captured by ERA-Int (Figs. 4e,h). In the cold season, the improvement of Tair trend magnitude in the WRF simulation in the central TP is somewhat balanced by the deterioration in the northeastern TP, which results in the same warming rate as ERA-Int in the dry season (Fig. 4d). Interestingly, the WRF simulation shows larger spatial correlation with observations than ERAInt (Table 3). The correlation for the WRF simulations passes the statistical two-tailed $t$ test at the $99.9 \%$ 
(a)

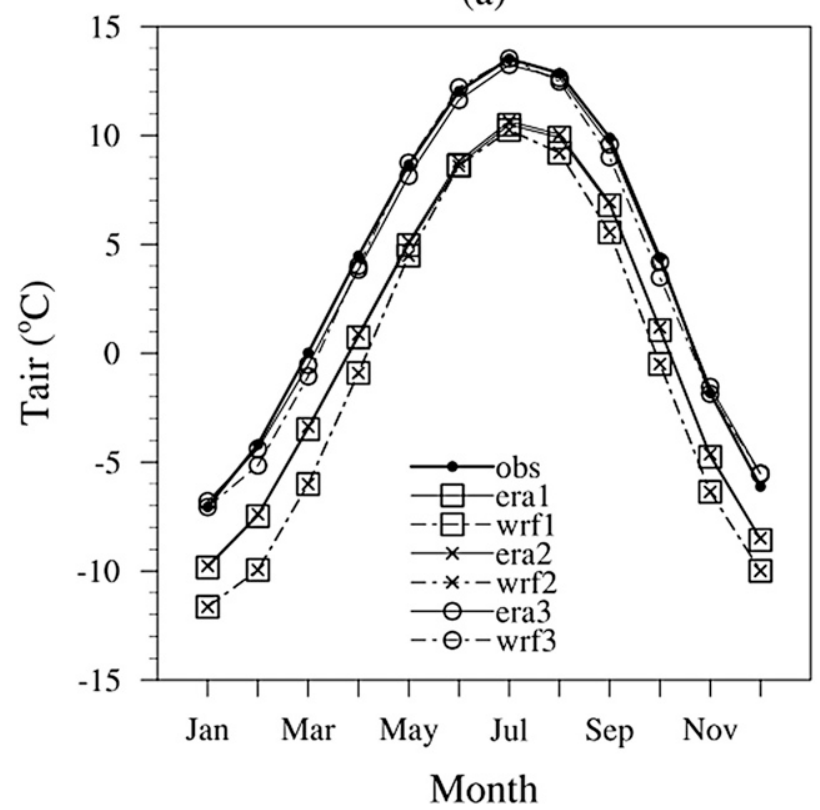

(b)

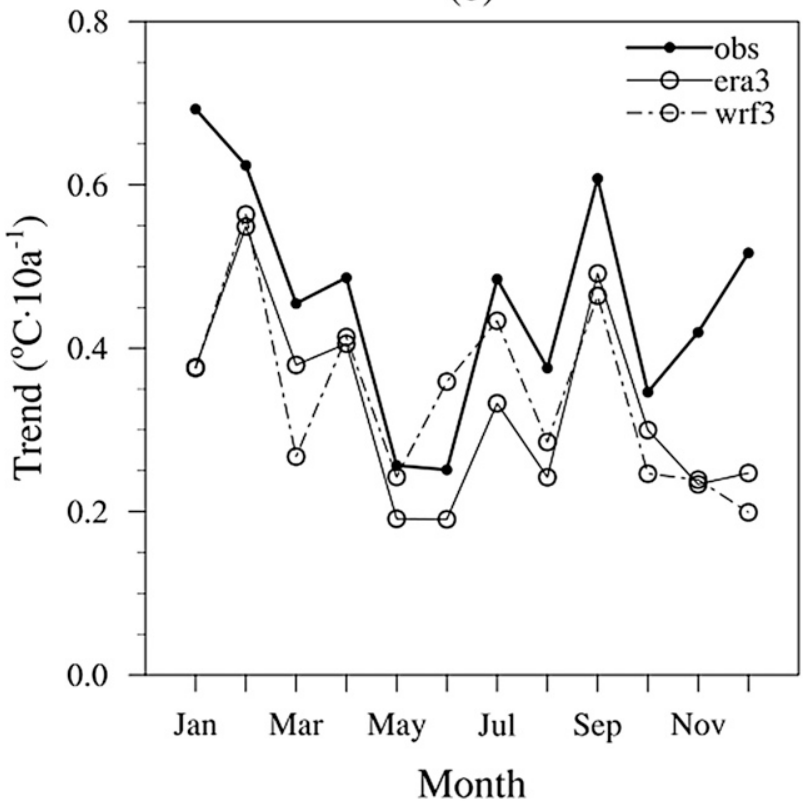

FIG. 2. Monthly-mean (a) Tair variation and (b) Tair trend in 1979-2011 averaged over all the stations for the observation (obs), ERA-Int (era), and WRF simulation (wrf). ( $1=$ results at the nearest grid cells; $2=$ after the interpolation; and $3=$ after lapse rate correction.)

confident level, which proves the added skill of WRF in simulating the regional warming pattern over the TP.

\section{b. Lapse rate}

Estimating the lapse rate requires temperature profile measurement, which hardly exists for a large region. Thus, in practice, near-surface air temperature measurements at a number of stations with different elevation in a region are regressed against the station elevations to provide an estimate of the lapse rate for the region (Fang and Yoda 1988; Li et al. 2013). Some previous studies claim an elevation dependency of Tair change over the TP (e.g., Qin et al. 2009), whereas others claim an absence of any elevation dependency in Tair trend over the TP (You et al. 2010). Recently, an increasing trend in the lapse rate over the western and a decreasing trend over the eastern TP in the lapse rate to the south of $35^{\circ} \mathrm{N}$ during the period of 1962 and 2011 have been found (Fig. 8 in Li et al. 2013). To find out if such an opposite change during our study period (19792011) also exists, we calculate the monthly lapse rates based on observed and simulated Tair to the south of $35^{\circ} \mathrm{N}$ in the TP. The temporal linear trends of Tair lapse rate was calculated using a slightly different approach from that of Li et al. (2013), which only considers elevation as the dependent variable and has a different period of time.

Figure 5a shows the observed interannual variability of the lapse rate in 1979-2011 for regions 18 (eastern TP) and 19 (western TP) as in Fig. 8 in Li et al. (2013), in which the lapse rate exhibits an opposite sign of change, with a decreasing trend for region 18 and an increasing trend for region 19. In Fig. 5a, however, the lapse rate estimated from the observations shows a downward trend for both regions, although only the trend for region 18 passes a significant $t$ test at the $95 \%$ confidence level. The reason for the disagreement between lapse rate trends revealed in this paper and in $\mathrm{Li}$ et al. (2013)

TABLE 2. Biases, root-mean-square error (RMSE), and spatial correlation coefficients (SCC) of the climatology in surface air temperature (Tair, ${ }^{\circ} \mathrm{C}$ ) of ERA-Int and the WRF simulations compared to the observations averaged over the 83 stations. Statistically significant SCCs at the $99.9 \%$ confidence level based on the two-tailed $t$ test are denoted with asterisks.

\begin{tabular}{|c|c|c|c|c|c|c|c|c|c|}
\hline & \multicolumn{3}{|c|}{ Bias } & \multicolumn{3}{|c|}{ RMSE } & \multicolumn{3}{|c|}{ SCC } \\
\hline & Dry & Wet & Annual & Dry & Wet & Annual & Dry & Wet & Annual \\
\hline ERA-Int & 0.07 & -0.34 & -0.18 & 1.96 & 1.42 & 1.70 & $0.95^{*}$ & $0.95 *$ & $0.95^{*}$ \\
\hline WRF & -0.30 & -0.20 & -0.32 & 2.51 & 1.81 & 2.17 & $0.92 *$ & $0.93 *$ & $0.93 *$ \\
\hline
\end{tabular}


(a) ERA-OBS(dry)

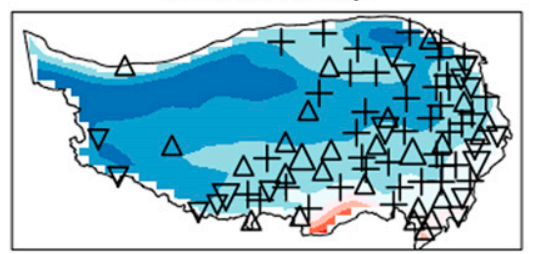

(d) WRF-OBS(dry)

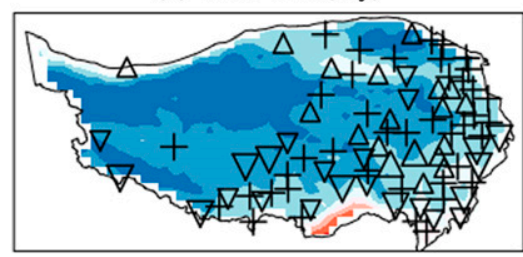

(b) ERA-OBS(wet)

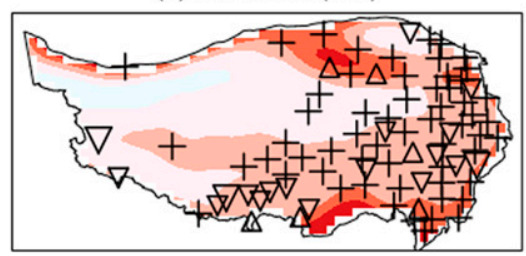

(e) WRF-OBS(wet)
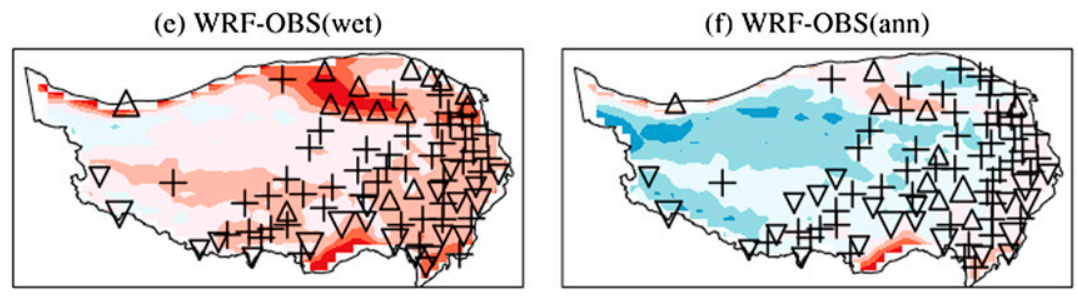

(c) ERA-OBS(ann)

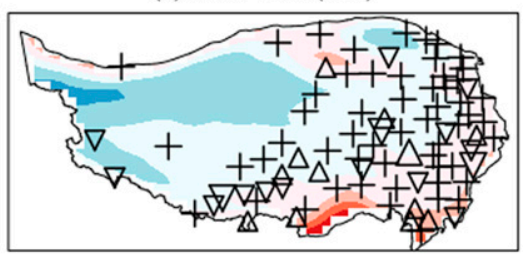

(f) WRF-OBS(ann)

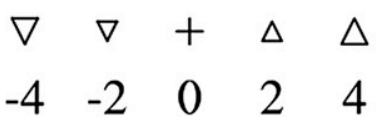

FIG. 3. Distribution of biases in monthly-mean Tair $\left({ }^{\circ} \mathrm{C}\right)$ in (a)-(c) ERA-Int and (d)-(f) the WRF simulation compared to the observations for the (left) dry and (center) wet seasons, and (right) annual mean in 1979-2011.

for the western TP may be due to the different stations and periods used. The difference in the estimating method may also have played a role. As there are many more stations in the eastern TP than in the western TP, the estimated lapse rate for the eastern region is considered more reliable. Both the results of Li et al. (2013) and our results indicate that Tair at higher altitude has experienced more warming (Fig. 6a). As presented in Figs. $6 \mathrm{a}$ and $7 \mathrm{a}$, only a small number of stations are located in the western TP and most of these are over $3800 \mathrm{~m}$, which is much higher than the stations in the eastern TP. From Fig. 6a we can see that the Tair change is elevation dependent over the whole TP in the observation, which is in consistent with the findings of Qin et al. (2009). The same elevation dependency of Tair changes was also revealed in studies over North America (Leung et al. 2003a; Kim et al. 2002; Gao et al. 2011b).

Figure 5c shows that the WRF simulation significantly improves the estimate of the lapse rate over the western TP, compared with that from ERA-Int (Fig. 5b). For the eastern TP, the ERA-Int estimate is close to that estimated from the observations, and the WRF simulation shows slightly lower values than those based on the observations. Theoretically, a dry lapse rate should be larger than a wet lapse rate. Since the western TP has a drier climate than the eastern TP, the lapse rate there is expected to be higher than that in the eastern TP as shown by both the observations and WRF simulation. However, the ERA-Int estimates illustrated in Fig. $7 \mathrm{~b}$ shows the opposite due to the underestimation in stations with elevations from 3500 to $4500 \mathrm{~m}$.

Opposite to the observation, ERA-Int displays an upward trend in the western TP (Fig. 5b) due to smaller warming in the central TP (Fig. 4f). At the same time, the WRF simulation displays a downward trend, as in the observations, although the decreasing rate is larger than the observed one. The lapse rate changes at the 83 stations over the TP using the neighboring grid cells are shown in our Fig. 8. The larger decreases in the lapse rate at higher elevations also indicate the elevation

TABLE 3. Observed trends in surface air temperature [Tair, ${ }^{\circ} \mathrm{C}$ (decade) $)^{-1}$ ] averaged over the 83 stations (obs) in comparison with those from ERA-Int and the WRF simulations. The mean values, biases, root-mean-square errors, and spatial correlation coefficients (SCC) of the results of ERA-Int and the WRF simulations are calculated with the observations as reference. Asterisks are as in Table 2.

\begin{tabular}{|c|c|c|c|c|c|c|c|c|c|c|c|c|}
\hline & \multicolumn{3}{|c|}{ Mean } & \multicolumn{3}{|c|}{ Bias } & \multicolumn{3}{|c|}{ RMSE } & \multicolumn{3}{|c|}{ SCC } \\
\hline & Dry & Wet & Annual & Dry & Wet & Annual & Dry & Wet & Annual & Dry & Wet & Annual \\
\hline Obs & 0.54 & 0.40 & 0.46 & & & & & & & & & \\
\hline ERA-Int & 0.36 & 0.29 & 0.33 & -0.18 & -0.11 & -0.13 & 0.33 & 0.23 & 0.25 & 0.11 & $0.43^{*}$ & 0.10 \\
\hline WRF & 0.33 & 0.36 & 0.34 & -0.21 & -0.04 & -0.12 & 0.32 & 0.20 & 0.23 & $0.32 *$ & $0.50 *$ & 0.28 \\
\hline
\end{tabular}


(a) $\operatorname{OBS}($ dry)

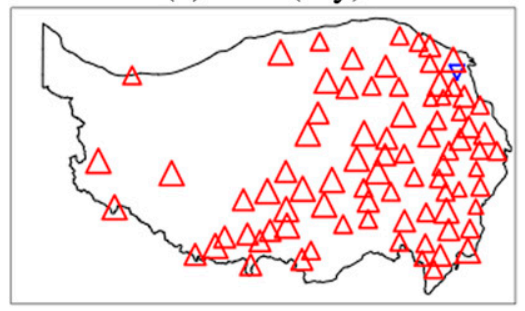

(d) $\operatorname{ERA}($ dry)

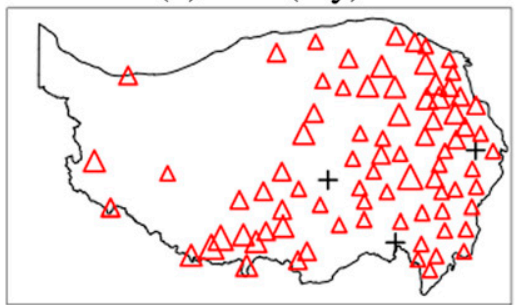

(g) WRF(dry)

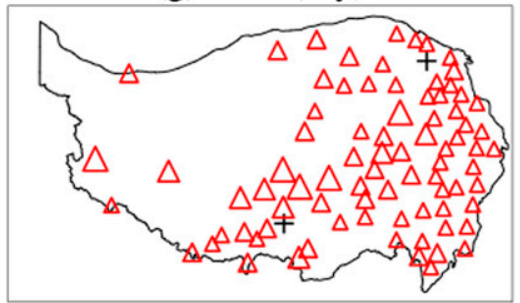

(b) OBS(wet)

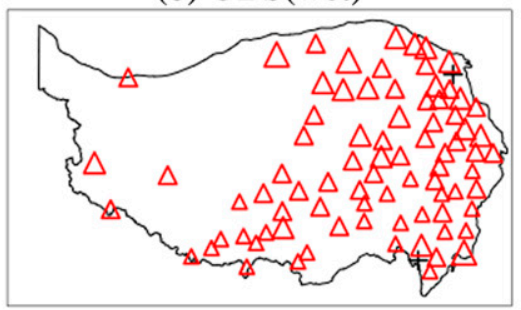

(e) $\operatorname{ERA}($ wet)

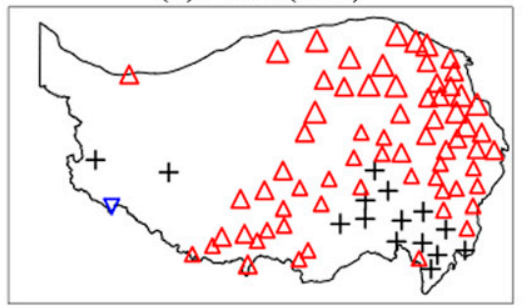

(h) WRF(wet)

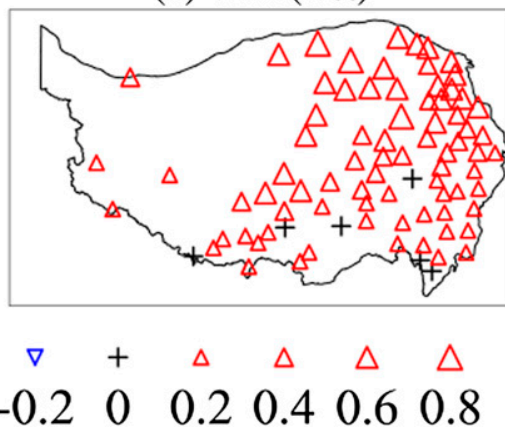

\section{$\begin{array}{llllll}-0.2 & 0 & 0.2 & 0.4 & 0.6 & 0.8\end{array}$}

(c) OBS(ann)

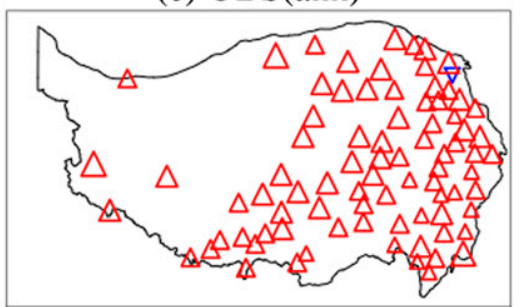

(f) ERA(ann)

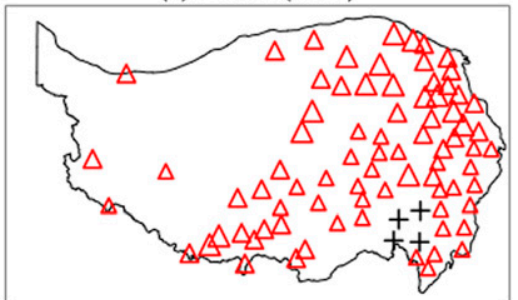

(i) WRF(ann)

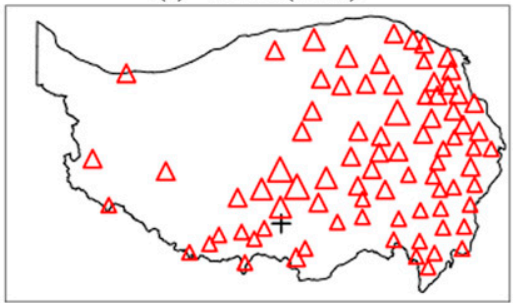

FIG. 4. Distribution of monthly-mean Tair trend $\left.\left[{ }^{\circ} \mathrm{C} \text { (decade }\right)^{-1}\right]$ in (a)-(c) observations, (d)-(f) ERA-Int, and (g)-(i) the WRF simulation for the (left) dry and (center) wet seasons, and (right) annual mean in 1979-2011.

dependency in the warming over the TP. Unfortunately, ERA-Int shows opposite changes.

The WRF simulation successfully reproduces the same trend sign as the observation in both western and eastern TP with significantly $(p=0.05)$ downward trends with the similar magnitude as the observation in the eastern TP (Fig. 5c). An exaggerated lapse rate trend in the western TP in the WRF simulation is shown in Fig. 5c, which is to a large extent caused by the large cold anomaly at high elevation in the dry season in 1982 . This anomaly is a result of an unusual low temperature anomaly at $500 \mathrm{hPa}$ in 1982 compared to climatology, which comes from the forcing. This deviation is amplified by the contrasted elevations of ups and downs in the finescale compared to the coarse-scale forcing. The magnitude and variability of the lapse rate in the WRF simulation matches the observation much better than ERA-Int, with higher spatial correlation coefficients in both the dry and wet seasons and smaller RMSE in the wet season (Table 3). Further, the elevation dependency in the observed Tair in the western and eastern TP is better reproduced by WRF than ERA-Int as shown in Figs. 6 and 7.

\section{c. Precipitation}

To examine the added value of the WRF simulation over ERA-Int for precipitation, Fig. 9 compares the observed annual cycle of the average precipitation and its temporal trend across the 83 stations, together with those from ERA-Int and the WRF simulation. It is clear that the Prec from the WRF simulation follows the observation in annual variation much better than those from ERA-Int (Fig. 9a). Prec is heavily overestimated in ERA-Int over the TP (Table 4; Figs. 9a and 10b). The WRF simulation approximately reduces $35 \%$ of the wet bias from the driving ERA-Int in the wet season although practically no improvement is noticed in the dry season (Fig. 9a; Table 4). As reflected in Fig. 10, which shows the bias distribution over the TP for ERA-Int and the WRF simulation, ERA-Int suffers from a large 


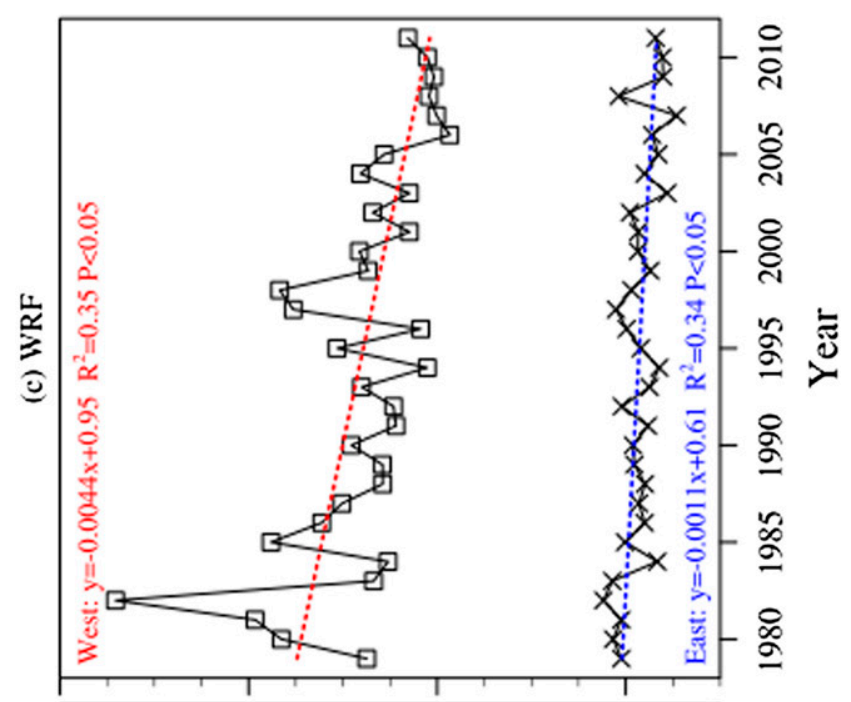

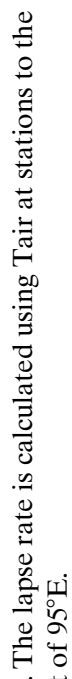

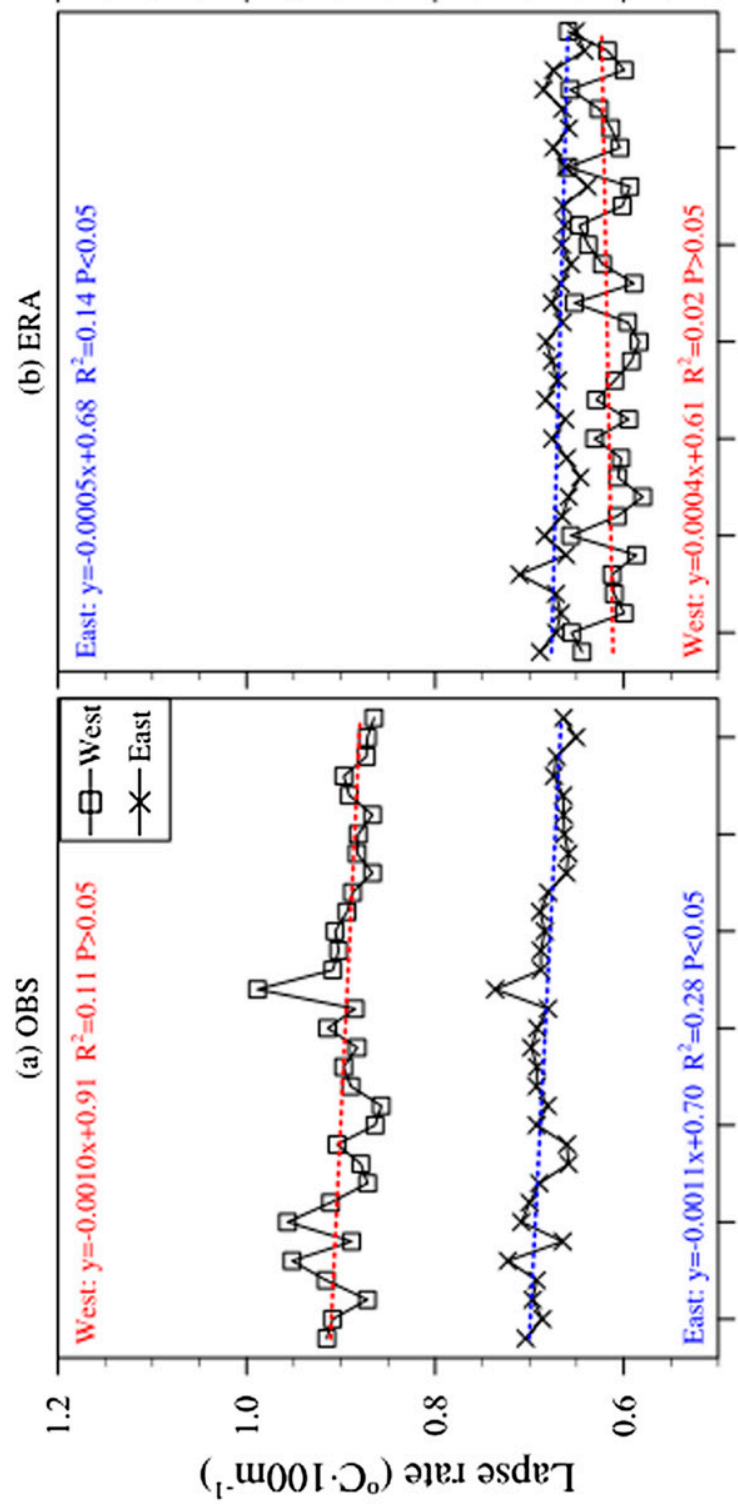

- 응

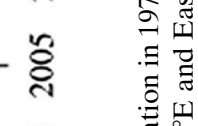

- ह

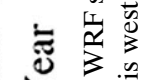

¿

各 ड़

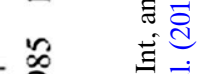

2 㐫示

\& है

응 $\quad 0$

ल ग

हु

- ह्व

4

$\frac{0}{\pi}$
$\frac{0}{0}$
0
0
0
0
0

$2>$

ஓ

年

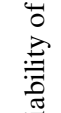

-

$\stackrel{\circ}{2}$ 


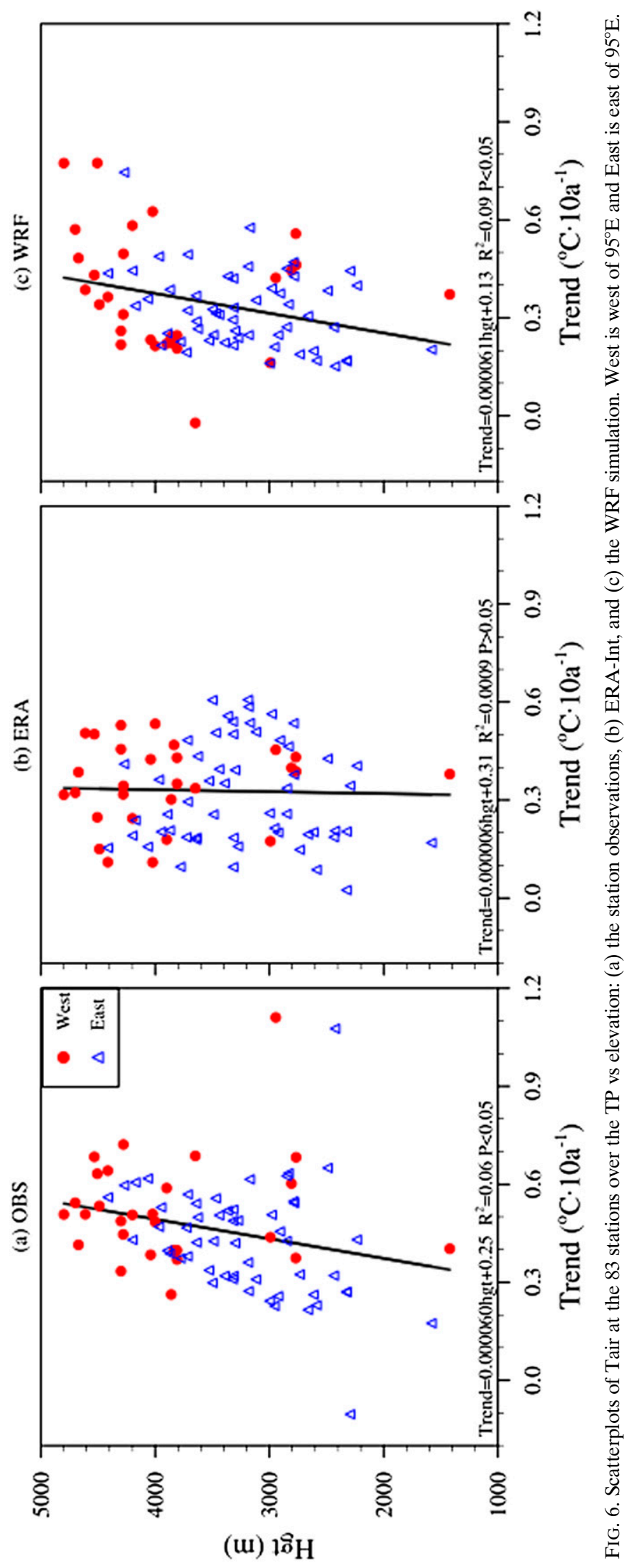



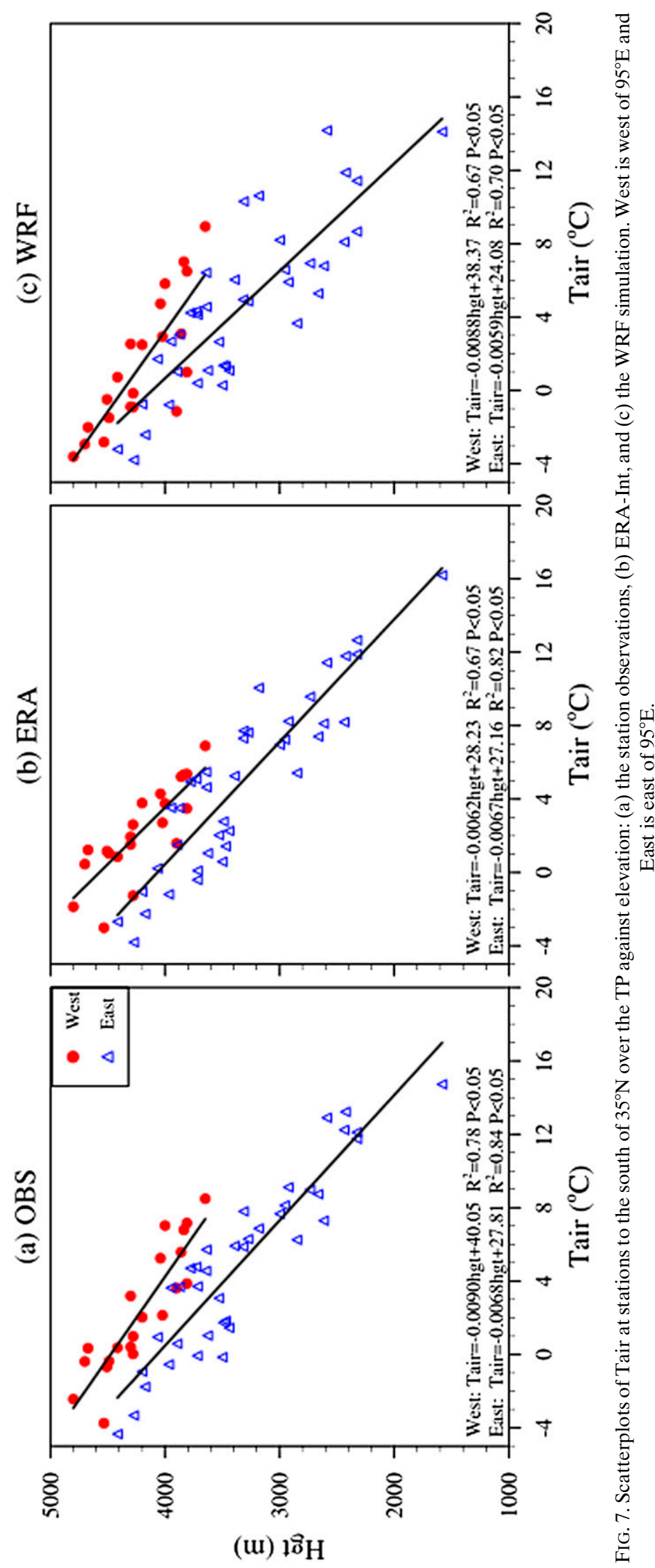
(a) ERA
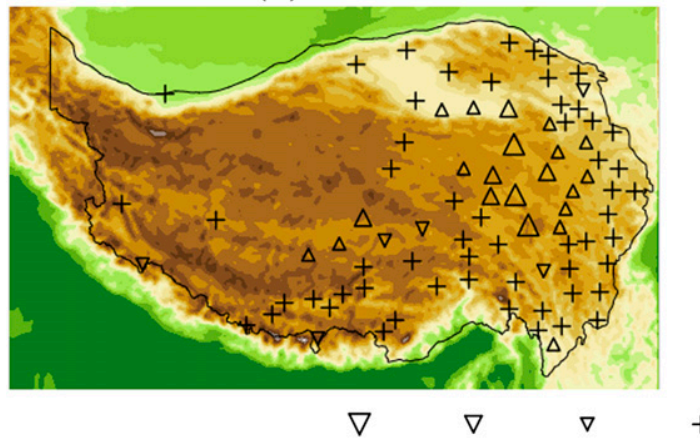

$\begin{array}{llll}-0.03 & -0.02 & -0.01 & 0\end{array}$ (b) WRF

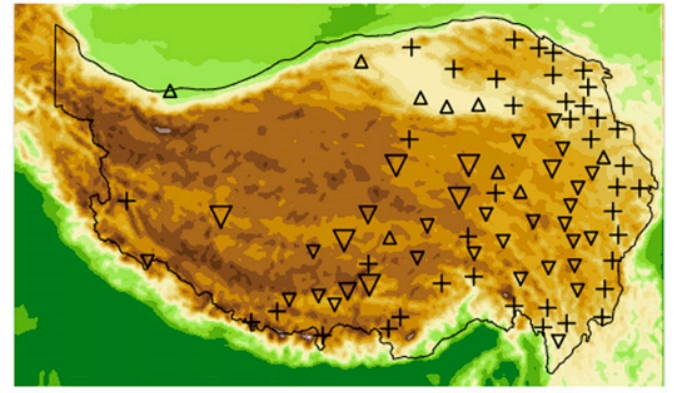

$\triangle$

FIG. 8. Lapse rate changes $\left[{ }^{\circ} \mathrm{C}(100 \mathrm{~m})^{-1}(\text { decade })^{-1}\right]$ at the 83 stations over the TP from (a) ERA-Int and (b) the WRF simulation.

amount of wet biases over the TP except the Chaidam basin in the wet season (Fig. 10b). In the dry season, wet biases mainly exist in the southern TP in ERA-Int (Fig. 10a), which was passed to the WRF simulation, showing a similar bias pattern (Fig. 10d; Table 4). In the wet season, not only are magnitudes of wet biases in the driving ERA-Int reduced in the WRF simulation, but also a higher spatial correlation with observations in the WRF simulation is gained compared with ERA-Int (Table 4). This is especially true in the central TP as several stations even show proximal zero bias (Fig. 10e). Annually, Figs. 10c and 10f show that larger wet biases exit in the southern TP than those in the central and northern TP in both ERA-Int and the WRF simulation.

Based on the observations, there are positive Prec trends for both the dry and wet seasons (Table 5). The largest increasing trend occurs in May followed by August (Fig. 9b), which accounts for a large portion of the increasing trend in the wet season $\left[0.024 \mathrm{~mm} \mathrm{day}^{-1}\right.$

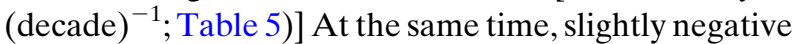
trends are found in July and September (Fig. 9b). Observed Prec in January-April has practically no trend, whereas it shows a slightly positive trend in the dry season due to an increase in October and November, despite a small decreasing trend in December. The observation presents no trend at most stations scattered with few stations with positive trend in the dry season (Fig. 11). In the wet season, there is a positive trend in the central and northern TP, which leads to the averaged positive trend although negative or no trends exist at several stations in the eastern TP. Annually, Prec presents positive trends in vast northwestern $\mathrm{TP}$ and no or negative trends in southeastern TP. The pattern similarity of the Prec trend between ERA-Int, the WRF simulation, and the observations is quite weak (Table 5), in line with the weak and scattered Prec trend in the observations.
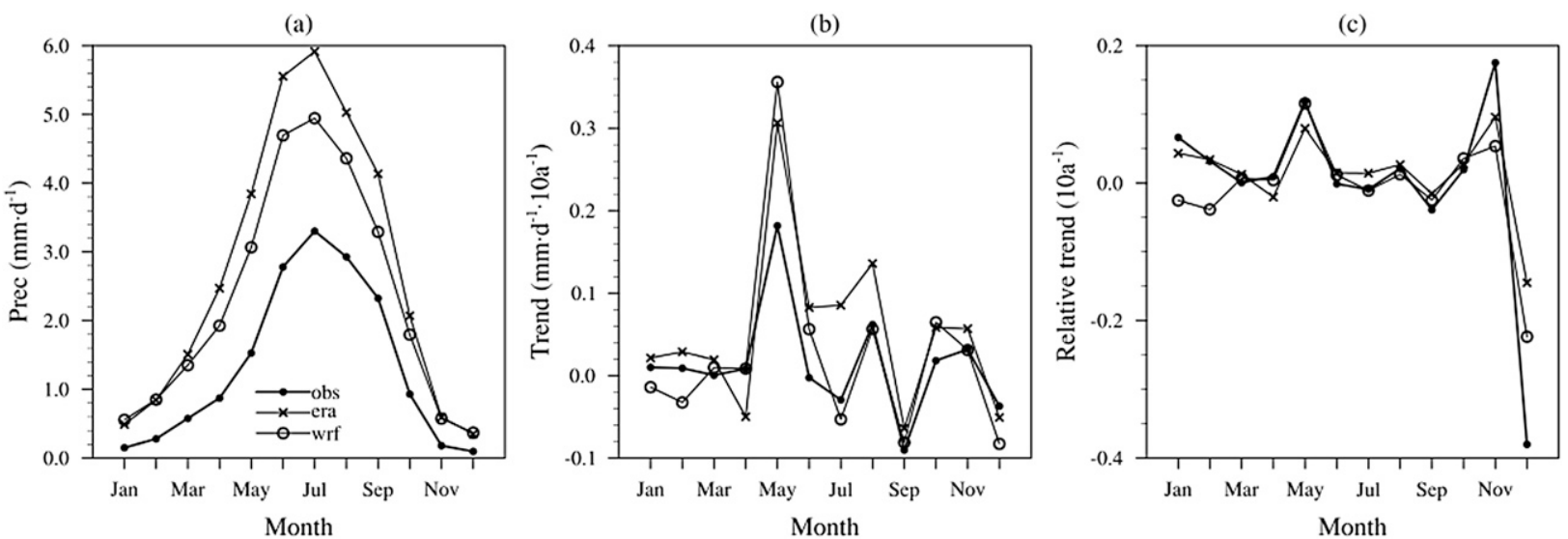

FIG. 9. Station averaged annual cycle of (a) Prec, (b) Prec trend, and (c) Prec relative trend in 1979-2011 for the observation (obs, black dots), ERA-Int (era, black crosses), and the WRF simulation (wrf, open circles). 
TABLE 4. Biases, root-mean-square errors, and spatial correlation coefficients (SCC) of the precipitation climatology (Prec, mm day ${ }^{-1}$ ) of ERA-Int and the WRF simulations as compared to the observations averaged over the 83 stations. Asterisks are as in Table 2 .

\begin{tabular}{|c|c|c|c|c|c|c|c|c|c|}
\hline & \multicolumn{3}{|c|}{ Bias } & \multicolumn{3}{|c|}{ RMSE } & \multicolumn{3}{|c|}{ SCC } \\
\hline & Dry & Wet & Annual & Dry & Wet & Annual & Dry & Wet & Annual \\
\hline $\begin{array}{c}\text { ERA- } \\
\text { Int }\end{array}$ & 0.50 & 2.32 & 1.40 & 1.06 & 3.65 & 2.60 & $0.52 *$ & $0.57 *$ & $0.63 *$ \\
\hline WRF & 0.48 & 1.50 & 0.99 & 1.17 & 2.66 & 2.01 & $0.64 *$ & $0.74 *$ & $0.75^{*}$ \\
\hline
\end{tabular}

ERA-Int presents much larger positive trend than the observation for the both seasons (Table 5), especially from May to August (Fig. 9b). Spatially, larger trends appear at stations on the east margin of the TP in the dry season and most stations in the wet season (Figs. 10d,e). Annually, ERA-Int presents the same trend pattern, which has much larger magnitude than the observations (Fig. 11f; Table 5).

Consistent with the observation and ERA-Int, the Prec trend in the WRF simulation shows the largest positive value in May and is closer to the observation than ERA-Int in July and August (Fig. 9b). The WRF simulation exhibits a scattered Prec trend pattern but with smaller magnitude than ERA-Int at most stations (Figs. 10g-i). It presents a large negative trend in December and February at Naqu, resulting in a negative trend in the dry season (Fig. 9b; Table 5).

Given the overestimation in Prec in the wet season in ERA-Int and the WRF simulation, monthly trends of relative changes are plotted in Fig. 9c. The WRF simulated trends are closer to the observations than those in ERA-Int in the wet season. This further confirms the added value of the WRF simulation.

\section{Conclusions}

A 33-yr WRF simulation driven by the ERA-Int over East Asia was conducted. The WRF simulated Tair and Prec over the TP are compared to observations at the 83 stations and to those from ERA-Int. The following conclusions are obtained.

1) For Tair, large cold biases exist in the WRF simulation and in ERA-Int. The cold bias in the WRF simulation primarily is inherited from ERA-Int. A comparison among the station heights and the elevation data used for the corresponding model cells in WRF and ERA-Int shows that the model elevations at grid scale are systematically higher than the station heights, which can explain a large part of the cold biases. Indeed, the cold biases are greatly reduced by the lapse rate correction in both ERA-Int and the
WRF simulation. Compared to ERA-Int and with the station observations as the reference, WRF is generally capable of more realistically reproducing the seasonal mean and long-term trend of Tair in the wet season, whereas no pronounced improvement is found in the dry season. Seasonal and annual mean Tair in observations shows a warming trend at all of the stations and the warming rate in the dry season is larger than that in the wet season. ERA-Int and the WRF simulation both show the same sign of Tair trend but with smaller magnitudes. In the wet season, the WRF simulation of Tair change is closer to the observations than ERA-Int.

2) The lapse rates estimated from the observations exhibit a decreasing temporal trend in both the eastern and western TP as a result of a larger warming rate at higher elevations. ERA-Int shows a larger lapse rate in the dry western TP than in moist eastern TP, which is not in accordance with the observations and the common understanding that lapse rate in a dry climate is larger than that in a wet one. Further, ERA-Int presents an inconsistent spatial pattern in the lapse rate trend with the observation, although the difference is small. The WRF simulation successfully reproduces consistent downward changes in the lapse rate in the western and eastern TP, just as the estimations from the observations show. The downward trend in the lapse rate in the whole TP confirms that the warming over the TP indeed increases with elevation in a warmer climate.

3) Annual variation of Prec in the WRF simulation matches the observation much better than that from ERA-Int. Prec is greatly overestimated in ERA-Int not only in the wet season but also in the dry season. However, the WRF simulation reduces the wet biases of ERA-Int by around $35 \%$.

4) Observed precipitation over the TP shows an upward trend in 1979-2011, which is mainly contributed by the precipitation change in the wet season. While the Prec trends for both the wet and dry seasons in ERAInt deviate significantly from those observed, the Prec trend for the wet season in the WRF simulation is much more realistic. The Prec trends for the dry season in both the WRF simulation and ERA-Int are close to each other and that of the observation.

This study has demonstrated the added value of the WRF simulation over the TP in terms of bias reduction, as well as a more realistic seasonal cycle, long-term trend, and spatial distribution for Tair and Prec. The improvements of the WRF simulations over those from ERA-Int come from the wet season dynamics, which 

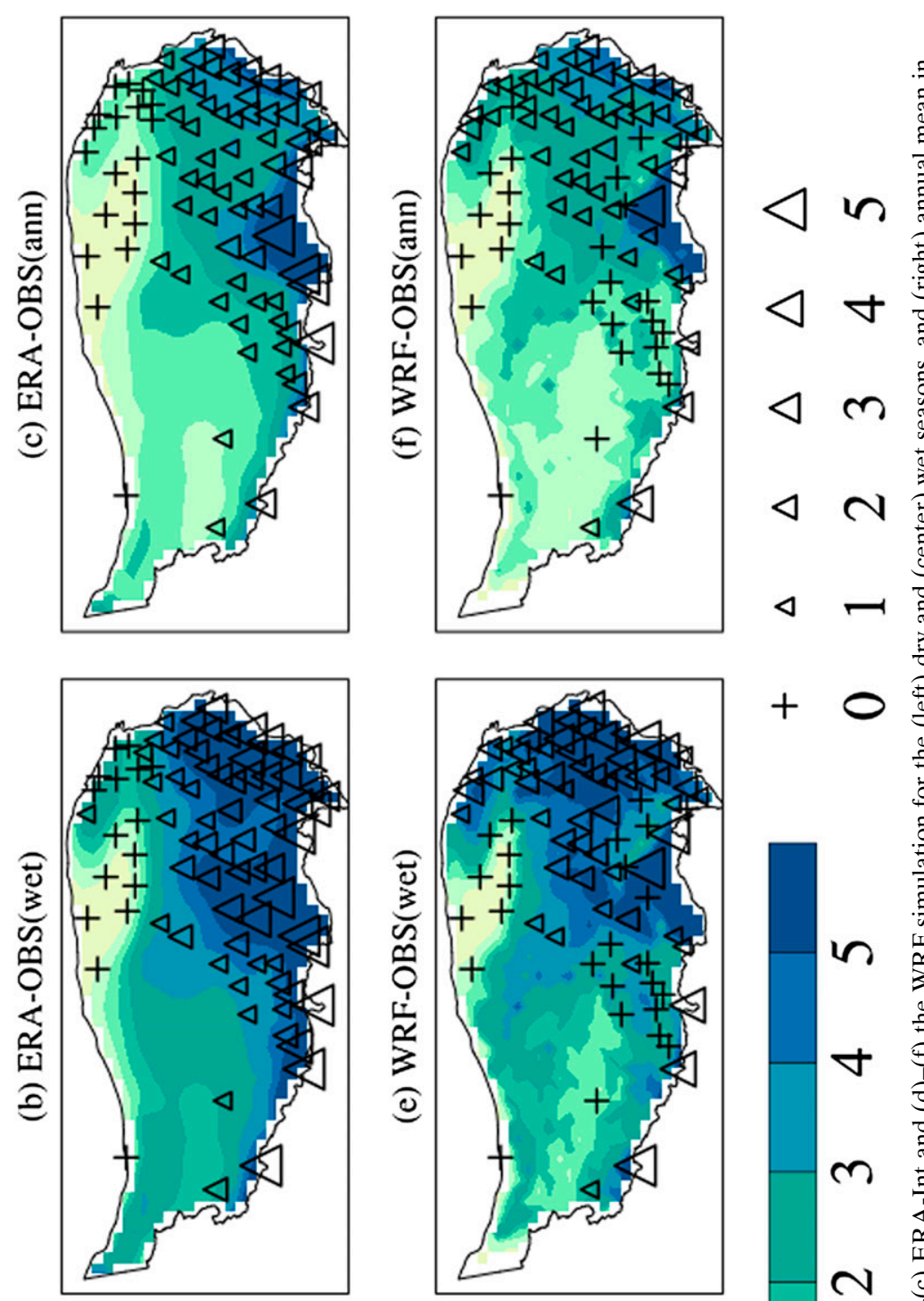

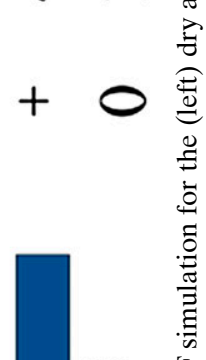

n

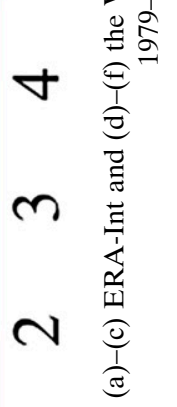
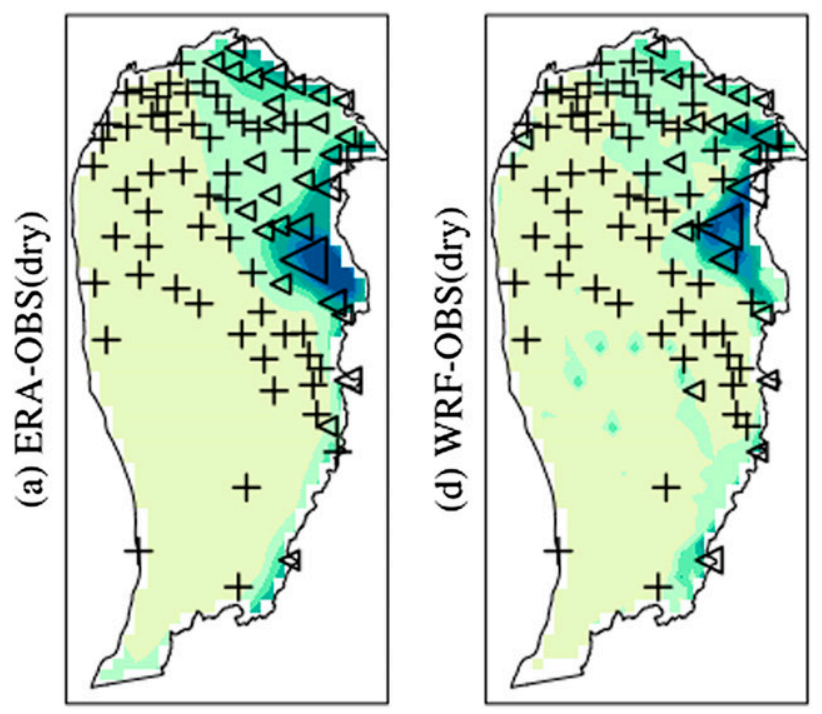

?

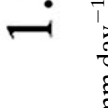

$\longrightarrow \quad \begin{aligned} & 0 \\ & 0 \\ & 0 \\ & 0 \\ & 0\end{aligned}$

0

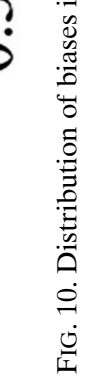




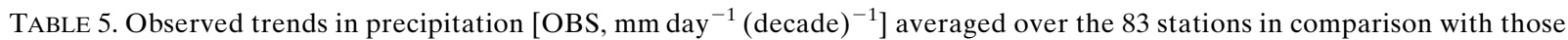
from ERA-Int and the WRF simulations. The mean values, biases, root-mean-square errors, and spatial correlation coefficients (SCC) of the results from ERA-Int and the WRF simulations are calculated with the observations as reference. Asterisk is as in Table 2 .

\begin{tabular}{|c|c|c|c|c|c|c|c|c|c|c|c|c|}
\hline & \multicolumn{3}{|c|}{ Mean } & \multicolumn{3}{|c|}{ Bias } & \multicolumn{3}{|c|}{ RMSE } & \multicolumn{3}{|c|}{ SCC } \\
\hline & Dry & Wet & Annual & Dry & Wet & Annual & Dry & Wet & Annual & Dry & Wet & Annual \\
\hline Obs & 0.003 & 0.024 & 0.013 & - & - & - & - & - & - & - & - & - \\
\hline ERA-Int & 0.015 & 0.109 & 0.053 & 0.012 & 0.085 & 0.039 & 0.06 & 0.29 & 0.16 & 0.03 & $0.50^{*}$ & 0.24 \\
\hline WRF & -0.018 & 0.067 & 0.027 & -0.021 & 0.043 & 0.013 & 0.13 & 0.18 & 0.12 & 0.02 & 0.13 & -0.20 \\
\hline
\end{tabular}

emphasizes the importance of processes linked to precipitation. The summer monsoon circulation seems to be the major contributor to the fact that improvement appears in the wet season, not in the dry season. Maintain ranges over the TP lie mainly in the west-east direction. In the wet season, the circulation over the TP flows more in poleward direction than meridional direction under control of the summer monsoon. The west-east orientation of the ranges functions as a protective screen facing the monsoon circulation. The strong uplifting by the windward slope may have caused the overestimation of Prec in ERA-Int. The ups and downs between ranges, which are smoothed in ERA-Int, are depicted vividly in WRF. The downs between ranges reduce the uplifting in the windward slope, which most likely leads to the improvements in WRF simulation in the wet season. However, in the dry season the westerly prevails. Not much difference in the uplifting occurs due to (a) OBS(dry)

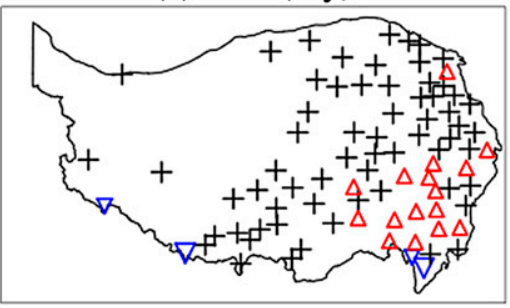

(d) ERA(dry)

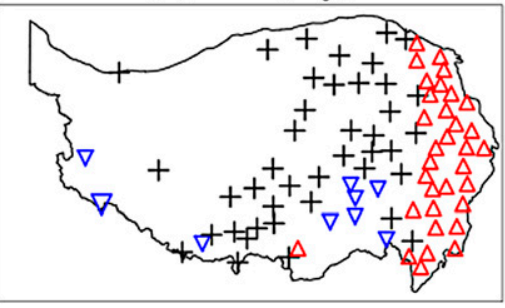

(g) WRF(dry)

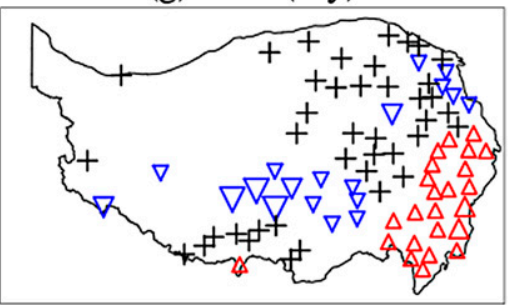

(b) OBS(wet)

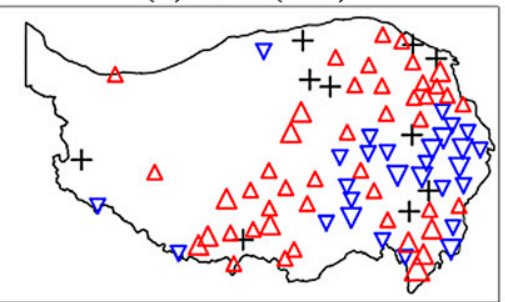

(e) ERA(wet)

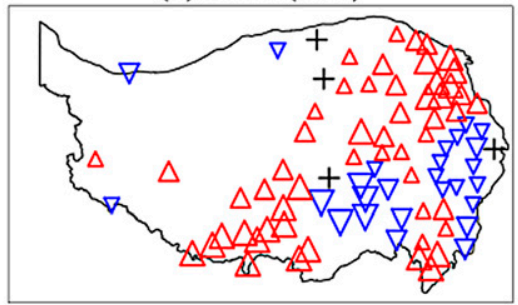

(h) WRF(wet)

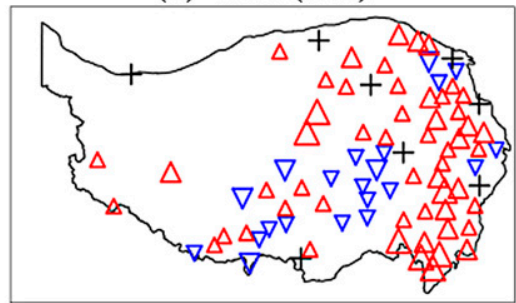

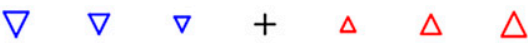

$\begin{array}{lllll}-0.4-0.2-0.1 & 0 & 0.1 & 0.2 & 0.4\end{array}$ (c) OBS(ann)

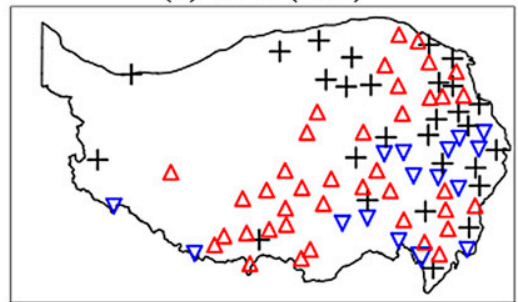

(f) $\operatorname{ERA}(a n n)$

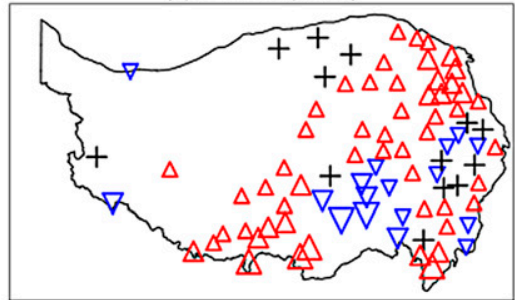

(i) $\mathrm{WRF}(\mathrm{ann})$

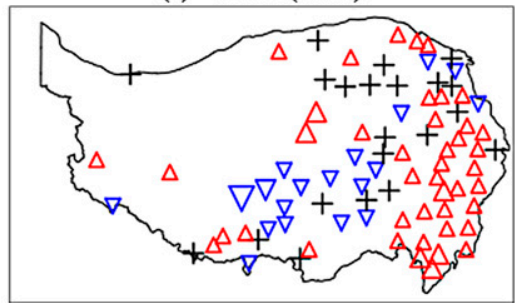

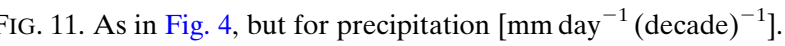


the west-east direction ranges. Hence, the monsoon circulation plays a major role in contributing to the improvement.

The fact that the important temperature-elevation relationship expressed by the lapse rate is more realistically reproduced in the WRF simulations compared to that in ERA-Int leads to the conclusion that the finescale WRF simulation better resolves important processes over the TP and can in general deliver more realistic temperature and precipitation information than the largescale driving climate for the region.

Finally, it should be noted that the $30-\mathrm{km}$ horizontal resolution is still not fine enough to resolve many complex local-scale processes over the TP. There is also a practical need to have finer-scale information for impact studies. These call for more reliable and finescale observation combining in situ and remotely sensed data and finer-scale modeling.

Acknowledgments. Ruby L. Leung and Tandong Yao are appreciated for the help in this study. The reanalysis data used in this study are from the Research Data Archive (RDA) that is maintained by the Computational and Information Systems Laboratory (CISL) at the National Center for Atmospheric Research (NCAR). This work is jointly supported by the Ministry of Science and Technology of China (2013CB956004), National Natural Science Foundation of China (41322033), and 100 Talents programme granted by the Chinese Academy of Sciences to Yanhong Gao. Deliang Chen is supported by a grant from the Swedish Research Council. We thank the Supper-Computing Center of Chinese Academy of Science for computing the simulations. We highly appreciate comments from three anonymous reviewers in improving the manuscript.

\section{REFERENCES}

Achberger, C., M.-L. Linderson, and D. Chen, 2003: Performance of the Rossby Centre regional atmospheric model in southern Sweden: Comparison of simulated and observed. Theor. Appl. Climatol., 76, 219-234, doi:10.1007/s00704-003-0015-6.

Adler, R. F., and Coauthors, 2003: The Version-2 Global Precipitation Climatology Project (GPCP) monthly precipitation analysis (1979-present). J. Hydrometeor., 4, 1147-1167, doi:10.1175/ 1525-7541(2003)004<1147:TVGPCP $>2.0$. CO;2.

Benestad, R. E., I. Hanssen-Bauer, and D. Chen, 2008: EmpiricalStatistical Downscaling. World Scientific, 300 pp.

Betts, A. K., S.-Y. Hong, and H.-L. Pan, 1996: Comparison of NCEP-NCAR reanalysis with 1987 FIFE data. Mon. Wea. Rev., 124, 1480-1498, doi:10.1175/1520-0493(1996)124<1480: CONNRW $>2.0 . \mathrm{CO} ; 2$.

Chen, D., T. Ou, L. Gong, C.-Y. Xu, W. Li, C.-H. Ho, and W. Qian, 2010: Spatial interpolation of daily precipitation in China: 1951-2005. Adv. Atmos. Sci., 27, 1221-1232, doi:10.1007/ s00376-010-9151-y.
Chen, F., and J. Dudhia, 2001: Coupling an advanced land surface-hydrology model with the Penn State-NCAR MM5 modeling system. Part I: Model implementation and sensitivity. Mon. Wea. Rev., 129, 569-585, doi:10.1175/ 1520-0493(2001)129<0569:CAALSH > 2.0.CO;2.

Collins, W. D., and Coauthors, 2004: Description of the NCAR Community Atmosphere Model (CAM 3.0). NCAR Tech. Note NCAR/TN-464+STR, 226 pp.

Dee, D. P., and S. Uppala, 2009: Variational bias correction of satellite radiance data in the ERA-Interim reanalysis. Quart. J. Roy. Meteor. Soc., 135, 1830-1841, doi:10.1002/qj.493. , and Coauthors, 2011: The ERA-Interim reanalysis: Configuration and performance of the data assimilation system. Quart. J. Roy. Meteor. Soc., 137, 553-597, doi:10.1002/ qj. 828.

Déqué, M., and Coauthors, 2005: Global high resolution versus limited area model climate change projections over Europe: Quantifying confidence level from PRUDENCE results. Climate Dyn., 25, 653-670, doi:10.1007/s00382-005-0052-1.

Duffy, P. B., and Coauthors, 2006: Simulations of present and future climates in the western United States with four nested regional climate models. J. Climate, 19, 873-895, doi:10.1175/ JCLI3669.1.

Entekhabi, D., I. Rodriguez-Iturbe, and F. Castelli, 1996: Mutual interaction of soil moisture state and atmospheric processes. J. Hydrol., 184, 3-17, doi:10.1016/0022-1694(95)02965-6.

Fang, J.-Y., and K. Yoda, 1988: Climate and vegetation in China (I). Changes in the altitudinal lapse rate of temperature and distribution of sea level temperature. Ecol. Res., 3, 37-51, doi:10.1007/BF02348693.

Gao, X., Z. Zhao, Y. Ding, R. Huang, and F. Giorgi, 2001: Climate change due to greenhouse effects in China as simulated by a regional climate model. Adv. Atmos. Sci., 18, 1224-1230, doi:10.1007/s00376-001-0036-y.

_ , Y. Xu, Z. Zhao, J. Pal, and F. Giorgi, 2006: On the role of resolution and topography in the simulation of East Asia precipitation. Theor. Appl. Climatol., 86,173-185, doi:10.1007/ s00704-005-0214-4.

—, Y. Shi, D. Zhang, J. Wu, F. Giorgi, Z. Ji, and Y. Wang, 2012: Uncertainties in monsoon precipitation projections over China: Results from two high-resolution RCM simulations. Climate Res., 52, 213-226, doi:10.3354/cr01084.

Gao, Y., and Coauthors, 2008: Enhancement of land surface information and its impact on atmospheric modeling in the Heihe River Basin, northwest China. J. Geophys. Res., 113, D20S90, doi:10.1029/2008JD010359.

_ J. A. Vano, C. Zhu, and D. P. Lettenmaier, 2011a: Evaluating climate change over the Colorado River basin using regional climate models. J. Geophys. Res., 116, D13104, doi:10.1029/ 2010JD015278.

, Y. Xue, W. Peng, H. Kang, and D. Waliser, 2011b: Assessment of dynamic downscaling of the extreme rainfall over East Asia using a regional climate model. Adv. Atmos. Sci., 28, 1077-1098, doi:10.1007/s00376-010-0039-7.

_ , L. R. Leung, E. P. Salathe, F. Dominguez, B. Nijssen, and D. P. Lettenmaier, 2012: Moisture flux convergence in regional and global climate models: Implications for droughts in the southwestern United States under climate change. Geophys. Res. Lett., 39, L09711, doi:10.1029/2012GL051560.

- L. Cuo, and Y. Zhang, 2014: Changes in moisture flux over the Tibetan Plateau during 1979-2011 and possible mechanisms. J. Climate, 27, 1876-1893, doi:10.1175/ JCLI-D-13-00321.1. 
Ghan, S. J., T. Shippert, and J. Fox, 2006: Physically based global downscaling: Regional evaluation. J. Climate, 19, 429-445, doi:10.1175/JCLI3622.1.

Giorgi, F., G. T. Bates, and S. J. Nieman, 1992: Simulation of the arid climate of the southern Great Basin using a regional climate model. Bull. Amer. Meteor. Soc., 73, 1807-1822, doi:10.1175/1520-0477(1992)073<1807:SOTACO > 2.0.CO;2.

_ - J. Colin, and A. Ghassem, 2009: Addressing climate information needs at the regional level: The CORDEX framework. WMO Bull., 58, 175-183.

Grell, G. A., 1993: Prognostic evaluation of assumptions used by cumulus parameterizations. Mon. Wea. Rev., 121, 764-787, doi:10.1175/1520-0493(1993)121<0764:PEOAUB > 2.0.CO;2.

Hirakuchi, H., and F. Giorgi, 1995: Multi-year present day and $2 \times$ $\mathrm{CO} 2$ simulations of monsoon dominated climate over eastern Asia and Japan with a regional climate model nested in a general circulation model. J. Geophys. Res., 100, $21105-$ 21 126, doi:10.1029/95JD01885.

Hong, S.-Y., and H.-L. Pan, 1996: Nonlocal boundary layer vertical diffusion in a medium-range forecast model. Mon. Wea. Rev., 124, 2322-2339, doi:10.1175/1520-0493(1996)124<2322: NBLVDI $>2.0 . \mathrm{CO} ; 2$.

Jacob, T., J. Wahr, W. T. Pfeffer, and S. Swenson, 2012: Recent contributions of glaciers and ice caps to sea level rise. Nature, 482, 514-518, doi:10.1038/nature10847.

Ju, L., H. Wang, and D. Jiang, 2007: Simulation of the Last Glacial Maximum climate over East Asia with a regional climate model nested in a general circulation model. Palaeogeogr. Palaeoclimatol. Palaeoecol., 248, 376-390, doi:10.1016/ j.palaeo.2006.12.012.

Kim, J., T. K. Kim, R. W. Arritt, and N. L. Miller, 2002: Impacts of increased atmospheric $\mathrm{CO}_{2}$ on the hydroclimate of the western United States. J. Climate, 15, 1926-1942, doi:10.1175/ 1520-0442(2002)015<1926:IOIACO > 2.0.CO;2.

Krause, P., S. Biskop, J. Helmschrot, W.-A. Flügel, S. Kang, and T. Gao, 2010: Hydrological system analysis and modelling of the Nam Co basin in Tibet. Adv. Geosci., 27, 29-36, doi:10.5194/adgeo-27-29-2010.

Laprise, R., D. Caya, M. Giguere, G. Bergeron, H. Côté, J. P. Blanchet, G. J. Boer, and N. A. McFarlane, 1998: Climate and climate change in western Canada as simulated by the Canadian Regional Climate Model. Atmos.-Ocean, 36, 119-167, doi:10.1080/07055900.1998.9649609.

Leung, L. R., Y. Qian, and X. Bian, 2003a: Hydroclimate of the western United States based on observations and regional climate simulation of 1981-2000. Part I: Seasonal statistics. J. Climate, 16, 1892-1911, doi:10.1175/1520-0442(2003)016<1892: HOTWUS $>2.0 . \mathrm{CO} ; 2$.

,-- J. Han, and J. O. Roads, 2003b: Intercomparison of global reanalyses and regional simulations of cold season water budgets in the western United States. J. Hydrometeor., 4, 10671087, doi:10.1175/1525-7541(2003)004<1067:IOGRAR > 2.0.CO;2.

_ , Y.-H. Kuo, and J. Tribbia, 2006: Research needs and directions of regional climate modeling using WRF and CCSM. Bull. Amer. Meteor. Soc., 87, 1747-1751, doi:10.1175/ BAMS-87-12-1747.

Li, S., S. Lv, Y. Gao, and Y. Zhang, 2005: Effect of different horizontal resolution on simulation of precipitation in Qilian Mountain (in Chinese). Plateau Meteor., 24, 496-502.

Li, X., L. Wang, D. Chen, K. Yang, B. Xue, and L. Sun, 2013: Nearsurface air temperature lapse rates in the mainland China during 1962-2011. J. Geophys. Res. Atmos., 118, 7505-7515, doi:10.1002/jgrd.50553.
Liu, X., and B. Chen, 2000: Climatic warming in the Tibetan Plateau during recent decades. Int. J. Climatol., 20, 1729-1742, doi:10.1002/ 1097-0088(20001130)20:14<1729::AID-JOC556>3.0.CO;2-Y.

Mearns, L. O., W. Gutowski, R. Jones, R. Leung, S. McGinnis, A. Nunes, and Y. Qian, 2009: A regional climate change assessment program for North America. Eos, Trans. Amer. Geophys. Union, 90, 311, doi:10.1029/2009EO360002.

Meehl, G. A., C. Covey, K. E. Taylor, T. Delworth, R. J. Stouffer, M. Latif, B. McAvaney, and J. F. Mitchell, 2007: The WCRP CMIP3 multimodel dataset: A new era in climate change research. Bull. Amer. Meteor. Soc., 88, 1383-1394, doi:10.1175/ BAMS-88-9-1383.

Mitchell, T. D., and P. D. Jones, 2005: An improved method of constructing a database of monthly climate observations and associated high-resolution grids. Int. J. Climatol., 25, 693-712, doi:10.1002/joc.1181.

Moore, G. W. K., 2012: Surface pressure record of Tibetan Plateau warming since the 1870s. Quart. J. Roy. Meteor. Soc., 138, 1999-2008, doi:10.1002/qj.1948.

Plummer, D., and Coauthors, 2006: Climate and climate change over North America as simulated by the Canadian RCM. J. Climate, 19, 3112-3132, doi:10.1175/JCLI3769.1.

Qin, J., K. Yang, S. Liang, and X. Guo, 2009: The altitudinal dependence of recent rapid warming over the Tibetan Plateau. Climatic Change, 97, 321-327, doi:10.1007/ s10584-009-9733-9.

Randall, D. A., and Coauthors, 2007: Climate models and their evaluation. Climate Change 2007: The Physical Science Basis, S. Solomon et al., Eds., Cambridge University Press, 589-662.

Skamarock, W. C., J. B. Klemp, J. Dudhia, D. O. Gill, D. M. Barker, W. Wang, and J. G. Powers, 2005: A description of the advanced research WRF version 2 . NCAR Tech. Note NCAR/ TN-468+STR, 88 pp. [Available online at http://wrf-model.org/ wrfadmin/docs/arw_v2.pdf.]

Solomon, S., D. Qin, M. Manning, Z. Chen, M. Marquis, K. Averyt, M. M. B. Tignor, and H. L. Miller Jr., Eds., 2007: Climate Change 2007: The Physical Science Basis. Cambridge University Press, 996 pp.

Su, F., X. Duan, D. Chen, Z. Hao, and L. Cuo, 2013: Evaluation of the global climate models in the CMIP5 over the Tibetan Plateau. J. Climate, 26, 3187-3208, doi:10.1175/JCLI-D-12-00321.1.

Wang, A., and X. Zeng, 2012: Evaluation of multireanalysis products with in situ observations over the Tibetan Plateau. J. Geophys. Res., 117, D05102, doi:10.1029/ 2011JD016553.

Wilks, D. S., 1995: Statistical Methods in the Atmospheric Sciences: An Introduction. Academic Press, $467 \mathrm{pp}$.

Wu, J., and X. Gao, 2013: A gridded daily observation dataset over China region and comparison with the other datasets (in Chinese). Chin. J. Geophys., 56, 1102-1111, doi:10.6038/ cjg20130406.

Wu, S., Y. Yin, D. Zheng, and Q. Yang, 2007: Climatic trends over the Tibetan Plateau during 1971-2000. J. Geogr. Sci., 17, 141-151, doi:10.1007/s11442-007-0141-7.

$\mathrm{Wu}$, T., and Coauthors, 2010: The Beijing Climate Center atmospheric general circulation model: Description and its performance for the present-day climate. Climate Dyn., 34, 123-147, doi:10.1007/s00382-008-0487-2.

Xu, J., and Y. Gao, 2014: Validation of summer surface air temperature and precipitation simulation over Heihe River Basin. Plateau Meteor., 33, 937-946, doi:10.7522/ j.issn.1000-0534.2013.00149. 
Xu, Y., X. Gao, Y. Shen, C. Xu, Y. Shi, and F. Giorgi, 2009: A daily temperature dataset over China and its application in validating a RCM simulation. Adv. Atmos. Sci., 26, 763-772, doi:10.1007/s00376-009-9029-z.

Yao, T., and Coauthors, 2013: A review of climatic controls on $\delta^{18} \mathrm{O}$ in precipitation over the Tibetan Plateau: Observations and simulations. Rev. Geophys., 51, 525-548, doi:10.1002/rog.20023.

You, Q., S. Kang, N. Pepin, W.-A. Flügel, Y. Yan, H. Behrawan, and J. Huang, 2010: Relationship between temperature trend magnitude, elevation and mean temperature in the Tibetan Plateau from homogenized surface stations and reanalysis data. Global Planet. Change, 71, 124-133, doi:10.1016/ j.gloplacha.2010.01.020.
Yu, E., H. Wang, and J. Sun, 2010: A quick report on a dynamical downscaling simulation over China using the nested model. Atmos. Oceanic Sci. Lett., 3, 325-329.

Zhang, D., X. Gao, Z. Bai, and D. Li, 2005: Simulation of climate over Qinghai-Xizang Plateau utilizing RegCM3. Plateau Meteor., 24, 714-720.

, - - L. Ouyang, and W. Dong, 2008: Simulation of present climate over China by a regional climate model. J. Trop. Meteor., 14, 19-23.

Zhang, Y., V. Dulière, P. W. Mote, and E. P. Salathé, 2009: Evaluation of WRF and HadRM mesoscale climate simulations over the U.S. Pacific Northwest. J. Climate, 22, 5511-5526, doi:10.1175/2009JCLI2875.1. 